\title{
Article \\ Can Frequency Account for the Grammatical Choices of Children and Adults in Nominal Modification Contexts? Evidence from Elicited Production and Child-Directed Speech
}

\author{
Emanuela Sanfelici ${ }^{1, *(D)}$ and Petra Schulz ${ }^{2}$ (D) \\ 1 Department of Linguistic and Literary Studies, University of Padua, 35122 Padova PD, Italy \\ 2 Department of Psycholinguistics and Didactics of German, Goethe-University Frankfurt, \\ 60323 Frankfurt, Germany; P.Schulz@em.uni-frankfurt.de \\ * Correspondence: emanuela.sanfelici@unipd.it
}

Citation: Sanfelici, Emanuela, and Petra Schulz. 2021. Can Frequency Account for the Grammatical Choices of Children and Adults in Nominal Modification Contexts? Evidence from Elicited Production and ChildDirected Speech. Languages 6: 35. https://doi.org/10.3390/languages 6010035

Received: 20 December 2020

Accepted: 12 February 2021

Published: 26 February 2021

Publisher's Note: MDPI stays neutral with regard to jurisdictional claims in published maps and institutional affiliations.

Copyright: (c) 2021 by the authors. Licensee MDPI, Basel, Switzerland. This article is an open access article distributed under the terms and conditions of the Creative Commons Attribution (CC BY) license (https:/ / creativecommons.org/licenses/by/ $4.0 /)$.

\begin{abstract}
There is consensus that languages possess several grammatical variants satisfying the same conversational function. Nevertheless, it is a matter of debate which principles guide the adult speaker's choice and the child's acquisition order of these variants. Various proposals have suggested that frequency shapes adult language use and language acquisition. Taking the domain of nominal modification as its testing ground, this paper explores in two studies the role that frequency of structures plays for adults' and children's structural choices in German. In Study 1, 133 three- to sixyear-old children and 21 adults were tested with an elicited production task prompting participants to identify an agent or a patient referent among a set of alternatives. Study 2 analyzed a corpus of child-directed speech to examine the frequency of passive relative clauses, which children, similar to adults, produced very often in Study 1. Importantly, passive relatives were found to be infrequent in the child input. These two results show that the high production rate of rare structures, such as passive relatives, is difficult to account for with frequency. We claim that the relation between frequency in natural speech and use of a given variant in a specific context is indirect: speakers may opt for the less grammatically complex computation rather than for the variant most frequently used in spontaneous speech.
\end{abstract}

Keywords: frequency; relative clause; elicited production; passive; German; corpus; child-directed speech; passive subject relative clause

\section{Introduction}

Imagine you just got a phone call from one of your neighbors, who lives upstairs. The other day your dog bit him, and he called to let you know that his scratch is getting much better and you should not worry. When your husband asks you "Who called?" you could, in principle, respond with any of the options in $(1 \mathrm{a}-\mathrm{c})$ :

1. a. The neighbor who our dog bit.

b. The neighbor who was bitten by our dog.

c. The neighbor who was bitten.

d. \#The neighbor that bit our dog.

The responses $(1 \mathrm{a}-\mathrm{c})$ correctly describe the person who called. Assuming that there are several neighbors in your building but only one whom your dog bit, these responses succeed in unambiguously referring to this individual. That is, the meaning "our dog bit one of our neighbors and this is the neighbor who just called" can be expressed via different means, all involving modification of the noun "neighbor". (1a) illustrates modification via a relative clause (RC), in which the modified noun is the direct object of the transitive RC verb "bite"; following common terminology, these RCs are referred to as object relative clauses (ORCs). (1b) as well as (1c) illustrate the modification of the noun via a RC with 
a passive verbal form, with the meaning of the passive $\mathrm{RC}$ being equivalent to that of an ORC (see Contemori and Belletti 2014). The two variants in (1b,c) only differ regarding whether the agent PP is present or not. Crucially, a non-passivized relative clause, such as (1d), would lead to referential failure. Following common terminology, we refer to this type of $\mathrm{RC}$, in which the head of the RC is the subject of the RC predicate, as subject relative clause (SRC).

In German, speakers may answer the question just as in $(1 \mathrm{a}-\mathrm{c})$, translated in $(2 \mathrm{a}-\mathrm{c})$, or also with (2d) or (2e), depending on their dialect. In these cases, the RC is introduced by the uninflected complementizer wo "where" and not by the relative pronoun der/die/das "who", similar to the generalized use of "that" in English.

2. a. Der Nachbar, den unser Hund gebissen hat the.NOM neighbor who.ACC our.NOM dog bitten has

"The neighbor who our dog has bitten."

b. Der Nachbar, der von unser-em Hund gebissen wurde the.NOM neighbor who.NOM by our-DAT dog bitten was "The neighbor who was bitten by our dog."

c. Der Nachbar, der gebissen wurde the.NOM neighbor who.NOM bitten was "The neighbor who was bitten."

d. Der Nachbar, wo der Hund gebissen hat the.NOM neighbor where who.NOM dog bitten has "The neighbor that our dog has bitten."

e. Der Nachbar, wo (vo-m Hund) gebissen wurde the.NOM neighbor where (by-the.DAT dog) bitten was "The neighbor that was bitten (by the dog)."

The meaning conveyed by the grammatical variants mentioned in $(1 \mathrm{a}-\mathrm{c})$ and $(2 \mathrm{a}-\mathrm{e})$ is the same: they are instances of the many-to-one mapping between form and meaning. Accordingly, we can ask whether speakers prefer any of the clausal variants and what may drive their choices.

Take the example of ORCs: when prompted by discourse to modify a patient noun phrase (DP), as in our example (1) above, speakers rarely opt for ORCs (e.g., Gordon et al. 2002; Friedmann et al. 2009). In particular, ORCs, such as (1a), which involve a transitive predicate, with the agent and the patient denoting animate referents expressed by a lexical phrase, seem to be almost absent in adults' natural speech and are rarely produced by children in experimental production studies across many languages (Guasti and Cardinaletti 2003; Diessel and Tomasello 2005; Novogrodsky and Friedmann 2006; Adani et al. 2010; Contemori and Belletti 2014; Jensen de Lopez et al. 2014). To convey the intended meaning, speakers choose alternative structures, and these may not necessarily be the same across languages. Experimental findings revealed that children and adults opt for passive RCs in several but not all languages: the production of passive RCs has been reported for Italian (Contemori and Belletti 2014), Indonesian (Tjung 2006), Korean (Kim and OGrady 2016), Danish (Jensen de Lopez et al. 2014), Swedish (Håkansson and Hansson 2000), and German (Adani et al. 2012), but not for Hebrew (Friedmann et al. 2009), Catalan (Gavarrò et al. 2012), and Portuguese (Belletti and Costa 2015). Speakers of the latter languages often produced ORCs introduced by an uninflected complementizer and containing a resumptive pronoun. Likewise, German-speaking children and adults have been found to prefer wo-RCs $(2 \mathrm{a}, \mathrm{b})$ over RCs introduced by a relative pronoun (Adani et al. 2012).

Although variation across languages exists, the choice of the specific grammatical variants is likely to not be arbitrary. It is still unresolved, however, whether speakers' choices reflect frequencies in the ambient language or language-internal factors. That is, do the preferred grammatical variants have in common that they are frequent or that they are grammatically less complex than full ORCs, independent of frequency (see Adani et al. 2012; Contemori and Belletti 2014)? In the current study, we investigate to what extent corpus frequencies determine the types of grammatical variants used in nominal modification 
contexts. Starting from the working assumption that frequency guides language use and language acquisition, we also ask whether the preferred options change in the course of acquisition. We address these issues in two studies: Study 1 investigates the grammatical variants that German-speaking 3- to 6-year-olds and adults use when asked to modify agent and patient DPs. Taking as a starting point the main result of Study 1-the surprisingly frequent use of passive RCs-Study 2 examines the frequency and the properties of passives and passive RCs in child-directed speech and compares this data to the characteristics of passive RCs in our experimental data of Study 1.

The structure of the paper is as follows: Section 2 provides an overview of how agent and patient DPs can be modified in German and delineates the frequency account. Section 3 reviews previous findings regarding the use of SRCs and ORCs and their variants in adult and child language. Section 4 describes the elicited production experiment (Study 1), and Section 5 describes the analysis of child-directed speech (Study 2). Section 6 offers a discussion of our findings and points to some limitations and suggestions for further research, Section 7 concludes the paper.

\section{Noun Modification in German and the Role of Frequency}

In this section we describe the various means that speakers may use to modify a noun, in case the referent needs to be specified by supplying additional information. For ease of comparison, we use the scenario in the Introduction in which an animate agent performs an action on an animate patient. To abstract away from the influence of world knowledge on the expected reading (e.g., neighbor, dog, bite), we use several cartoon animal figures which perform silly actions; the corresponding pictures were used in Study 1.

\subsection{Modifying an Agent DP}

Imagine you are shown the picture in Figure 1 and you are asked Welcher Affe hat einen Hut auf? "Which monkey is wearing a hat?". Note that, in this picture, there are two monkeys, and thus, in order to single out the right one, you need to specify something unique about the monkey wearing the hat.

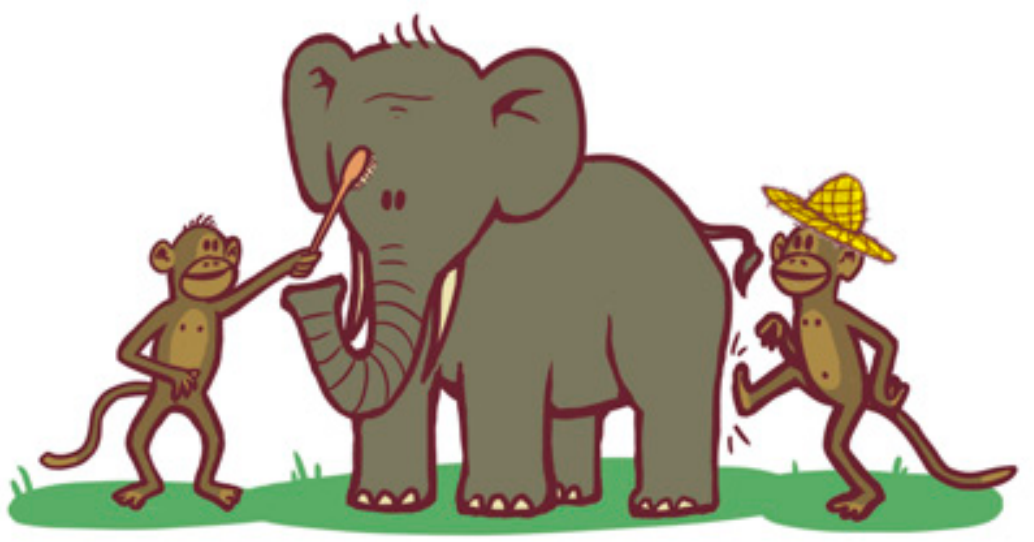

Figure 1. Modifying the agent of an action.

Various answers are possible in response to such a question: the one to the right for example. However, suppose your hearer cannot see the picture. In this case, this answer would be inappropriate and the range of possible answers narrows down. Still, there are several structures one can use, exemplified in $(3 a, b)$. For ease of reference, we refer to the nominal phrase that is modified as the RC head. 
3. a. Der Affe der/ wo den Elefanten tritt the.NOM monkey who.NOM/where the.ACC elephant kicks "The monkey which/where is kicking the elephant."

b. Der den Elefanten tretende Affe the.NOM the.ACC elephant kicking monkey "The monkey kicking the elephant."

Speakers may use an SRC introduced by a relative pronoun as der "who" in (3a). German RCs are post-nominal and typically exhibit the finite verb in sentence-final position. ${ }^{1}$ The relative pronoun der/die/das "who" must be marked for gender, number and case. ${ }^{2}$ The relative pronoun agrees in gender and number with the nominal expression, e.g., monkey in (3a), and it bears the case assigned by the RC-internal predicate. Accordingly, the case of the relative pronoun may differ from the case assigned to the RC head. Speakers may also use a SRC with an uninflected complementizer, such as was "that/what" or wo "that/where" in (3a): these are functional elements that usually appear in complement clauses or locative adverbial clauses. Importantly, the functional element does not agree with the RC head and does not carry case.

Speakers could also opt for adjectival modification by using a present participle as in ( $3 \mathrm{~b})$. These are morphologically complex elements, composed of a verb stem and the suffix -end, expressing progressive present tense. Their mode is active: the modified noun is interpreted as the subject argument of the verb. Like adjectives, present participles agree in case, number, and gender with the nominal expression they modify, e.g., monkey in (3b).

Note that, in the structures $(3 a, b)$, the RC head is expressed by a lexical expression, monkey. Depending on the context and the specific question asked, speakers could also use a pronominal expression. For instance, given the picture in Figure 1 and the question "Which monkey is wearing the hat?", one could also answer der, der den Elefanten tritt "the one who is kicking the elephant".

\subsection{Modifying a Patient DP}

Imagine you are shown the picture in Figure 2 and you are asked Welcher Esel hat einen Hut auf? "Which donkey is wearing the hat?". As there are two donkeys, you need to add specific information about the donkey wearing the hat.
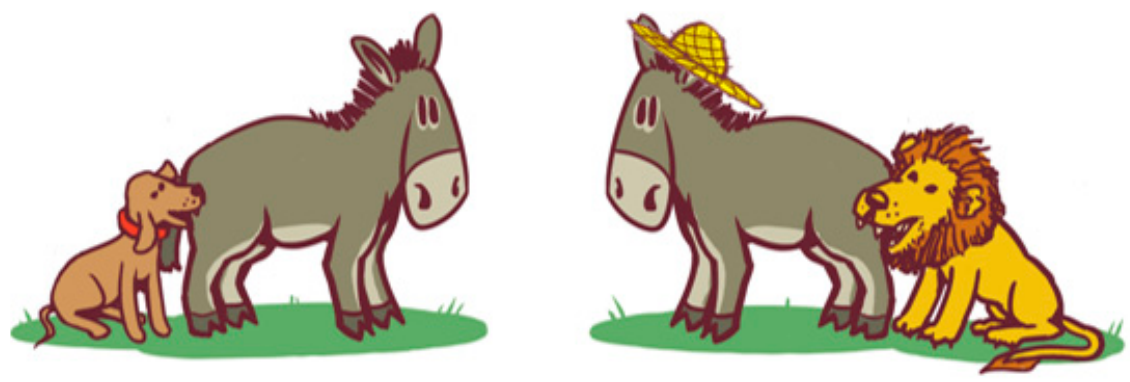

Figure 2. Modifying the patient of an action.

Again, assuming that your hearer cannot see the picture, you may answer with any of the variants illustrated in (4):

1 Under certain conditions, the verb may appear in V2 (see Gärtner 2001; Sanfelici et al. 2017).

2 Due to syncretism in the inflectional paradigm of German, only the masculine singular form of the relative pronoun differs in its overt morphological realization in nominative vs. accusative case (der vs. den). 
4. a. Der Esel den der Löwe beißt

the.NOM donkey who.ACC the.NOM lion bites

"The donkey which the lion bites."

b. Der Esel wo der Löwe (ihn) beißt

the.NOM donkey where the.NOM lion (him) bites

"The donkey that the lion bites (him)."

c. Der Esel der/wo vo-m Löwe-n gebissen

the.NOM donkey who.NOM/where by-the.DAT lion-DAT bitten

wird

becomes

"The donkey which/that is bitten by the lion."

d. Der vo-m Löwe-n gebissen werdende Esel

the.NOM by-the.DAT lion-DAT bitten becoming donkey

"The donkey bitten by the lion."

Speakers may opt for an ORC introduced by a relative pronoun, as in (4a). Alternatively, the ORC may be introduced by the invariant complementizer wo, as in (4b), which may also contain a personal pronoun resuming the modified nominal expression, e.g., ihn "him". In addition, speakers may opt for an SRC with a passivized predicate, illustrated in (4c), introduced by either a relative pronoun or by an uninflected complementizer. Note that in this case the RC predicate consists of the auxiliary werden "become" and the past participle form of the lexical verb (e.g., gebissen "bitten"). The prepositional phrase headed by the preposition von encodes the agent of the action. As in the case of agent modification, speakers may use a pronoun instead of the lexical head noun, e.g., der den der Löwe beißt "the one who the lion bites". Finally, speakers may employ adjectival modification by using the past participle and the prepositional phrase encoding the agent as illustrated in (4d). Past participles are morphologically composed of the verb stem, the suffix - $t$ or $-e n$, and often the prefix ge- (see Zifonun et al. 1997).

\subsection{Which Variant to Choose: The Role of Frequency}

Comparing the possible answers to the question "Which $\mathrm{x}$ is wearing the hat?" in (3) to those in (4), we see that the range of grammatical variants in German is higher in patient modifying than agent modifying contexts. ${ }^{3}$ In case a speaker needs to identify the unique referent in a context with several competing referents, which of the variants does she actually use and for what reason? Informally speaking, the following scenarios are conceivable: different speakers may prefer different structures, or a speaker may use different variants at different times, as a result of free variation. In these two scenarios, all variants may occur with equal frequency in one population but not necessarily in one speaker. Alternatively, a speaker may use specific structures due to the influence of additional factors. More precisely, assuming that the adult competent speaker is aware of the existing variants, at some point in her utterance planning will she have to decide which variant to produce. All variants share the function of modifying a lexical nominal expression ("monkey/donkey"); hence, the speaker succeeds in identifying the unique referent, no matter which variant she uses. How does a speaker decide? In the following we look critically at the possible role of frequency.

Speakers' choices of one or several specific variants have been argued to be driven by frequency: the variants most frequently heard in the ambient language are the ones the speaker opts for in a given discourse context. Frequency is typically defined in terms of number of occurrences of a given linguistic structure in a particular linguistic (sub)system, as approximated by a suitable corpus. The basic rationale is as follows: the more frequently a construction occurs, the more deeply entrenched it is in the speaker's mental grammar. This construction will be easily activated in language use, appear earlier in acquisition, and win in situations of language change (Bybee and Hopper 2001; Diessel and Tomasello

Naturally, the existence of a specific variant depends on the specific morpho-syntactic properties of German. To illustrate, (3b) does not exist in Italian, since no "active" participle is available except in few lexicalized instances (Cinque 2017). 
2005; Bybee 2006; Diessel 2009, 2019, a.o.). More specifically, if a form is the most frequent in absolute terms (i.e., absolute frequency), speakers are likely to produce this form, and, given two competing forms, the more frequent one in relative terms (i.e., relative frequency) will be used with greater likelihood (e.g., Ambridge et al. 2015). Although it is not difficult to determine intuitively what counts as more frequent, the decision of which categories enter into the comparison is rather difficult to determine. Accordingly, various studies have employed different measures of frequency and have often reached different conclusions as to which type of frequency influences adults' and children's language use. ${ }^{4}$ We address this issue in Section 3, summarizing previous findings for adult use and child acquisition of noun modification.

\section{Previous Findings}

\subsection{Frequency of Subject/Object RCs and Their Variants in German Adult Speech}

We saw that in theory adult speakers can choose among several grammatical variants that all succeed in modifying the agent or patient of an action. So, what do speakers produce in a specific situation? Corpus data are assumed to reflect the reality of adults' speech with a high degree of likelihood (e.g., Roland et al. 2007); below, we review the main findings from corpus studies examining the structures in (3) and (4).

In both the agent- and patient-modifying contexts, participle constructions are reported to be rare in the majority of studies (Pakkanen-Kilpiä 2004; Struckmeier 2007; Lübbe and Rapp 2011). Investigating English-German translation texts from the Oslo Multilingual Corpus, Hansen-Schirra et al. (2007) found that the German version used finite RCs more often than non-finite constructions, including participles (see also Hansen and HansenSchirra 2012). Apart from its rare use, a high degree of individual and stylistic variation has been noted, with participles sometimes being preferred over RCs (Weber 1971; Doherty 2006; Fabricius-Hansen 2010). Studies on child-directed speech have not investigated the rate of participle constructions.

RCs seem to be the preferred structure when speakers need to modify the agent or the patient of an action. As for the elements introducing the $\mathrm{RC}$, dialect research finds that the choice of the pronoun or the uninflected complementizer varies according to the geographical area of speakers. Whereas RCs in Standard Modern German are generally introduced by a relative pronoun, some German varieties, including Alemannic, Northern German dialects, and Bavarian, may use complementizers such as wo "that/where" or was "that/what" (Fleischer 2004, p. 218; Brandner and Bräuning 2013). The detailed corpus analyses by Hirschberg et al. (2014) confirm this dialectal pattern, based on audio recordings in Standard German (Vorleser Corpus) and on recordings of northern German dialect speakers (Lindenstraße Corpus). In the Vorleser Corpus $81 \%$ of all extracted RCs (403/498) were introduced by forms of the relative pronoun der/die/das. Relatively few RCs were introduced by was "that/what" $(n=82)$ or wo "that/where" $(n=12)$; these occurrences were all expected in Standard German (e.g., free RCs, locative meaning of wo). In the Lindenstraße Corpus, in contrast, out of the $80 \mathrm{RCs}$ extracted, the relative pronouns der/die/das accounted for only one third of all RCs produced (24/80); 70\% of the RCs (56/80) were introduced by an uninflected complementizer, not restricted to a locative meaning or free RCs. As in the case of participle structure, we are not aware of any study on RCs introduced by the uninflected complementizer in child-directed speech.

In agent-modifying contexts, adults are reported to opt for SRC structures; these SRCs were all of the same type: they contained an intransitive predicate (Bader and Koukoulioti 2018; Mak et al. 2002, 2006; Adani et al. 2017). Bader and Koukoulioti (2018) extracted 644 RCs randomly drawn from the deWac corpus (Baroni et al. 2009), a German corpus of texts collected from the Internet (1.2 billion tokens). The authors found that SRCs were very frequent $(n=547)$, compared to the ORCs $(n=97)$, and that they mainly consisted of

4 As a case in point, Kieburg and Schulz (2010) employed a range of different frequency measures for the parental input regarding verb particles in German and found that these measures made very different predictions regarding children's use of these verb particles. 
an intransitive predicate with a lexical DP (72\% of all SRCs). A similar observation was made in Mak et al. (Mak et al. 2002) based on a corpus studies of German newspaper texts, (Die Welt, four editions, for a total of 75,000 words). Adani et al. (2017) investigated the properties of SRCs and ORCs in child-directed speech for three German-speaking children from the CHILDES corpus. The authors extracted a total of 307 RCs: 134 SRCs and 173 ORCs. The majority of the adult SRCs $(76 \%, n=102)$ contained either a copular or an intransitive predicate, and only $32(24 \%)$ contained a transitive predicate. Out of the 205 RCs with a transitive predicate, only few were SRCs $(16 \%, n=32)$; the majority were ORCs $(84 \%, n=173)$.

In the patient-modifying context, adults are reported to produce both ORCs and passive RCs. The type of ORC most frequently attested in the corpora comprises a pronominal element as a subject, a transitive predicate, and a lexical inanimate noun as the RC head (e.g., the house that she bought). Bader and Koukoulioti (2018) found in their analysis of the deWac corpus that, out of the 97 ORCs, the majority $(67 \%, n=65)$ contained a subject pronoun and a lexical inanimate noun as the RC head. Similarly, Adani et al. (2017) reported that, in the child-directed speech corpora, the majority of the $205 \mathrm{RCs}$ with a transitive predicate were ORCs $(84 \%, n=173)$, most of which modified an inanimate nominal expression $(n=141)$, whereas only 24 contained an animate noun as the RC head.

As for passives, studies to date provide a diverse picture with respect to adults' preferred structure, as well. In an analysis of the 644 RCs extracted from the deWac corpus, Bader and Koukoulioti (2018) found that passive RCs were more frequent than ORCs: 97 sentences contained an ORC, compared to 154 sentences with a passive RC, of which 18 had a lexicalized agent-like PP. At the same time, studies examining the occurrences of werden "to become" as a passive marker in child-directed speech found passives to be rare. Abbot-Smith and Behrens (2006) reported a total of only 84 tokens of werden passives in $63 \mathrm{~h}$ of adult child-directed speech. Likewise, based on an analysis of four child-directed speech corpora, Zombolou and Alexiadou (2015) conclude that werden passives hardly ever occurred. These results leave open whether passive constructions are rare in child-directed speech only or whether the frequency of passive RCs may have been overestimated in previous studies on adult speech.

In summary, the growing research on corpus frequency of modifying structures provides evidence that some structural variants occur more often than others and that the basis of comparison strongly influences the outcome. As our brief summary shows, variation exists regarding the types of corpora, e.g., child-directed speech, spoken adult language or web written texts, and regarding the measures of the grammatical variants proposed. Accordingly, it is not easy to predict speakers' choices in a concrete discourse situation. Given the inconclusive results for passives and ORCs, for instance, it is not clear whether adults will opt for a passive SRC or an ORC, when shown Figure 2. In addition, the status of participial structures is unclear from the corpus studies we reviewed. Certain speakers may opt for participial structures independent of their overall infrequency. Finally, while corpus studies agree in claiming that, in general, SRCs are far more frequent than ORCs, the picture seems to be reversed when the RC predicate is transitive: in this case ORCs are very frequent and SRCs are rare. Note that, in Figure 1, just like in Study 1, predicates were transitive. Hence, it is unclear what adults would do in such a context.

\subsection{Occurrence of Subject/Object RCs and Their Variants in German Child Language}

Besides allowing insight into the make-up of adults' speech, adult corpus data can inform us about the input children are exposed to. This is self-evident for adult childdirected speech, but may in principle also hold for adult speech in general, assuming that adult-adult speech and child-adult speech do not differ fundamentally. We return to this point in the discussion. Under the assumption that corpus frequency determines both language use and acquisition (e.g., Diessel 2009, 2019; Ambridge et al. 2015), children's production is expected to closely resemble adults' production in general. At the same time, children do not, initially, speak or understand language in the way adults do. Adults have 
all (or at least several) existing grammatical variants at their disposal to express a specific meaning, whereas the language-learning child has most likely acquired only some of these variants. Accordingly, before asking which variants children prefer when modifying agents and patients (see (3) and (4)), we need to determine which of the structures the children can produce and at what age they first emerge. In the following section, we review previous acquisition studies on German that investigated the relevant structures here.

In general, children use fewer variants when modifying an agent than when modifying a patient. In agent-modifying contexts, preschool children have been found to produce SRCs with either a relative pronoun or an uninflected complementizer, as exemplified in (3a) (Rothweiler 1993; Diessel and Tomasello 2005; Adani et al. 2012). Children are also reported to produce SRCs with a pronominal RC head (Adani et al. 2012, 2017), parallel to what has been found in adults (see Section 2.1). To our knowledge, the production of participial constructions, as in (3b), has not been investigated, so we do not know whether children use them and, if so, at what age.

When prompted to modify the patient of an action, German-speaking children have been found to produce the structures listed in $(4 a-c)$ : ORCs introduced by a relative pronoun and by the uninflected complementizer wo "where", which may be accompanied by a resumptive pronoun in the RC, as well as passive RCs (Rothweiler 1993; Adani et al. 2012; Yatsushiro and Sauerland 2019). As in the case of agent modification, children sometimes use a pronoun instead of the lexical head noun. No acquisition studies we are aware of have reported information on the use of participial structures as in (4d). Finally, and differently from the adult data, many experimental studies provide evidence that children produce semantically inappropriate RCs, which do not match the depicted event or do not answer the right question (e.g., Yatsushiro and Sauerland 2019). For example, given Figure 2, children would produce (5), which is an SRC with the patient as the RC head noun and the wrong thematic roles.

\section{Der Esel der/wo den Löwe beißt \\ the.NOM donkey who.NOM/where the.ACC lion bites \\ "The donkey which/that bites the lion."}

A large body of research based on spontaneous speech corpora and on elicited production tasks revealed pronounced differences regarding the age at which these variants emerge in German. German-speaking children start producing SRCs around age 3;0 or even earlier, in spontaneous speech (e.g., Rothweiler 1993; Brandt et al. 2008) and in experimental settings (e.g., Diessel and Tomasello 2005; Adani et al. 2012). The production of ORCs lags behind that of SRCs. Children start producing ORCs in spontaneous speech around age 4 (Rothweiler 1993; Brandt 2004; Brandt et al. 2008), and in experimental studies, 4and 5-year-olds had more difficulty with ORCs, that require two animate nouns such as that in (4a), than with SRCs (Diessel and Tomasello 2005; Adani et al. 2017). However, 3and 4-year-olds correctly produced ORCs with an inanimate RC head and a pronominal subject, which also frequently appear in adult speech. This type of ORC was in fact not more difficult for children than production of SRCs (Kidd et al. 2007).

Results on RCs with an uninflected complementizer are inconclusive: this variant was found in some studies (Adani et al. 2012, 2017; Yatsushiro and Sauerland 2019), but not in others (Kidd et al. 2007; Brandt et al. 2008). It should be noticed that the former studies recruited children from the same geographical area (Potsdam), which suggests the influence of dialectal variation. Furthermore, experimental studies reported the use of semantically inappropriate ORCs by German-speaking children up to age 5 (Diessel and Tomasello 2005; Kidd et al. 2007; Adani et al. 2012, 2017; Yatsushiro and Sauerland 2019).

Finally, let us turn to the variant of passive RCs, which requires passive morphology and syntax to be in place. Studies on German passives have provided mixed results, with some reporting late and others early acquisition. Mills (1985), for instance, found that passives with a lexicalized agent (called "long passive") appeared around age 5 and were rarely used. Passives without the lexicalized agent (called "short passive") first occurred around age 4 in spontaneous speech (see also Fritzenschaft 1994). Eventive passives with 
the auxiliary werden "to become" appeared later than stative passives with the auxiliary sein "to be" (Mills 1985; Abbot-Smith and Behrens 2006). In contrast to Mills (1985) and Fritzenschaft (1994), Abbot-Smith and Behrens (2006) provided evidence for early emergence of passives in German children's spontaneous speech: passives first appeared around age 2;2 and were acquired by age 2;5 (see also Zombolou and Alexiadou 2015). Note, however, that these two studies did not distinguish between long and short passive.

The occurrence of passive RCs has been addressed in experimental studies only, involving children aged 5 and older, with conflicting results. Adani et al. $(2012,2017)$ found that passive RCs were produced at an even lower rate than ORCs in an elicited production task: when prompted to modify the patient of an action, 5-year-olds produced ORCs in $20 \%$ and passive RCs in $15 \%$ of the cases. Testing the same age group with a similar elicited production task, Yatsushiro and Sauerland (2019) report that, in the patient condition, children resorted to passive RCs (51 instances), and SEMANTICALLY INAPPROPRIATE RCS (61 instances), whereas ORCs (9 instances) were rarely produced. Accordingly, it is unclear whether, at age 5, children prefer passive RCs over ORCs, when asked to modify the patient of an action. Additionally, note that these studies investigated children from 5 years old onwards, starting at an age at which the production of complex structures is already in place and leaving open which pattern is found in younger children and in how far preferences change with development.

In summary, previous acquisition research has provided robust evidence that, when required to modify the agent or the patient of an action, children produce various structures that are similar to those used by adults, but not identical. Many questions remain unresolved. Little is known about whether children at age 3 and 4 have acquired passive RCs and would use them in an experimental setting and whether, in this case, they would prefer them over ORCs or not. It is also unclear which type of passive RC (e.g., long or short passive) is typical for children's use. Furthermore, we do not know whether and when children use participial structures in noun modification contexts. Finally, it remains unclear whether the use of uninflected complementizers in RCs is a matter of geographical variation or of avoidance of overt case, number, and gender marking required for relative pronouns.

\subsection{Summary and Open Issues}

Although the language system contains grammatical variants that may succeed equally well in modifying the agent or the patient of an action, adult speakers use different structures at different rates, as evidenced by a large body of corpus research. How a specific structure is ranked regarding its frequency crucially depends on what it is compared to, rendering the calculation of the frequency of a structure a non-trivial task. In our view the central question is which frequency calculation the speakers are sensitive to for it to shape language use and acquisition. Take for instance SRCs and ORCs: the total frequency of ORCs may be estimated on the basis of all clauses or on the basis of all structures modifying a noun. The relative frequency of ORCs could be calculated based on the total of SRCs and ORCs; passive RCs could be counted as a variant of SRCs or as a separate structure.

What is more, we may ask which comparison and, hence, which notion of frequency is relevant from the speaker's perspective. As illustrated with Figures 1 and 2, the situations in which an SRC or ORC are called for are very different. Maybe the need to modify a specific type of agent just occurs much more frequently in everyday life than the need to modify a specific type of patient. In this case it is the frequency of the specific situation that drives the frequency of SRCs and ORCs, for example (see also Roland et al. 2007). Only if the two types of situations occurred at the same rate, could we directly compare how speakers modify the agent and the patient of an action and would the possibility of producing an SRC and an ORC be the same. We consider our experimental design of Study 1 (see Section 4) to provide just this scenario.

When we turn to child language, the role of frequency is further complicated by development. Whereas adults may have the choice between all or most of the structures 
in (3) and (4), the children's pool of structures that they can choose from is smaller: they may have not yet acquired a specific structure. Accordingly, it is not easy to disentangle children's preferences among the variants already present in the child's grammar from evidence of the absence of a specific structure. Under an empirical perspective, the frequency of many structures, including passive RCs, RCs with an uninflected complementizer, and participial structures, in child-directed speech, as well as in child language, remains to be determined. We will address these issues in the two studies.

\section{Study 1: Elicited Production Task}

This study investigates which structures children and adults use when modifying agent and patient DPs, in order to examine whether corpus frequencies determine their choice of specific grammatical variants. We developed an elicited production task, which prompted participants to identify a referent among a set of alternative referents. Half of the situations required the modification of the agent and half modification of the patient, and all contexts displayed transitive events involving two animate participants. This design allows us to calculate and compare frequencies in a controlled setting. This way, we arrive at a measure of frequency that is distinct from "everyday language use", which unavoidably reflects conversational needs that may favor or disfavor production of one structure over another for language-unrelated reasons. Two research questions guided our analysis:

(Q1) Which grammatical variants of nominal modification do German children of different ages and adults prefer within a controlled experimental production task?

(Q2) Do the preferred variants change in the course of acquisition?

As for (Q1), we identified the range of structures produced by children aged 3, 4, 5 and 6 and by adults and then determine for each age group which ones are preferred, with the preference being measured in terms of production rates. As for $(\mathrm{Q} 2)$, we compare the data across the age groups to characterize the developmental path of the grammatical variants of nominal modification, starting at age 3 , the age at which production of complex sentences first emerges.

Our working assumption is that frequency shapes both language use and language acquisition (see Section 3.2). In our agent-modifying contexts, SRCs need an animate head and an animate RC internal direct object DP. Given the findings from corpus studies, it is unknown whether child and adult speakers would opt for this type of SRC: SRCs were reported to be the most frequent type of RC in German speakers, but they mainly consisted of intransitive or copula predicates. SRCs with transitive predicates were not frequently found in both adults' and children's spontaneous speech. In our patient-modifying contexts, ORCs need an animate head and an animate RC internal subject. Since this type of ORC was only rarely found in corpus studies, we did not expect participants to opt for ORCs. RCs with uninflected complementizers should occur only in speakers whose dialect allows this structure. Furthermore, we expected participial structures to be generally avoided in both contexts and to be restricted to individual preference. No clear predictions can be derived regarding passive RCs because detailed results on the frequency of passive RCs in adults' speech as well as on their acquisition to date are lacking. Finally, in the case of semantically inappropriate RCs it is impossible to derive frequency-based predictions: if the frequency of structures in the ambient language alone determined language acquisition, these constructions should not occur at all. Nevertheless, they have often been found in acquisition studies.

\subsection{Participants}

A total of 133 children between the ages of 3 and 6 were tested. Children were recruited in daycares in the metropolitan XXX area, and all parents gave written consent for their child's participation in the study. A parental questionnaire ensured that none of the children was bilingual, had signs of language impairment, language delay, or hearing problems. Moreover, all children were assessed with a standardized language test (SETK 
for ages 3 to 5, Grimm 2001; TROG-D for age 6, Fox 2006). Eleven children did not perform within the age-appropriate norms and were excluded from the analysis, and another eight children were excluded due to missing 8 or more items (out of 48 test items of our main test). In the following section, we report results on the remaining 114 typically developing monolingual German-speaking children. In addition, 21 adults with no background in linguistics were tested. The participants' details are summarized in Table 1.

Table 1. Description of participants.

\begin{tabular}{cccccc}
\hline & Age 3 & Age 4 & Age 5 & Age 6 & Adults \\
\hline Participants & $n=27$ & $n=31$ & $n=31$ & $n=25$ & $n=21$ \\
Sex & 14 girls & 18 girls & 16 girls & 8 girls & 9 women \\
\hline Age range & $3 ; 0-3 ; 11$ & $4 ; 0-4 ; 11$ & $5 ; 0-5 ; 11$ & $6 ; 0-6 ; 11$ & $19 ; 2-30 ; 9$ \\
\hline Mean age & $3 ; 7$ & $4 ; 5$ & $5 ; 5$ & $6 ; 4$ & $25 ; 0$ \\
SD in months & 3.2 & 3.8 & 2.78 & 3.4 & 43.9 \\
\hline
\end{tabular}

\subsection{Material and Procedure}

We developed a novel elicited production task involving colored pictures, which made the task suitable for young children. Nominal modification structures were elicited in a question-answer context similar to the design by Novogrodsky and Friedmann (2006). 24 test items prompted the production of structures in which the agent of an action was modified, and 24 test items prompted the production of structures in which the patient of an action was modified. Two warm-up items were included to familiarize participants with the experimental procedure. Each item was presented with a picture: (6) exemplifies the agent-modifying condition paired with Figure 3 and (7) the patient-modifying condition paired with Figure 4.

6. Test item in the modifying-agent condition

Context of elicitation

Hier sind zwei Bären, ein Hund, und ein Igel. Ein Bär wäscht den Hund und ein Bär wäscht den Igel. Welcher Bär hat den Hut auf?

"Here there are two bears, a dog, and a hedgehog. A bear is washing the dog and a bear is washing the hedgehog. Which bear is wearing the hat?"

Possible answer

Der Bär, der den Hund wäscht

"The bear that is washing the dog."

7. Test item in the modifying-patient condition

Context of elicitation

Hier sind zwei Affen und ein Hase. Der Hase streichelt einen Affen und er beißt einen Affen. Welcher Affe hat den Hut auf?

"Here, there are two monkeys and one hare. The hare is stroking one monkey and he is biting one monkey. Which monkey is wearing the hat?"

Possible answer

Der Affe, den der Hase beißt.

"The monkey that the hare is biting."

Parallel to the design by Novogrodsky and Friedmann (2006), the scenes showed either two contrasting actions (see Figure 4) or two contrasting participants (see Figure 2), all involving transitive events, expressed by transitive verbs. In order to minimize differences between the contexts modifying the agent and the patient, we selected only transitive verbs denoting reversible actions. The participants were all animal characters, so both animals were equally likely to perform these silly actions. All nouns used were animate referring to names of animals like bear, bird, etc. The test items contained only lexical DPs marked for masculine singular, providing unambiguous case-marking on the relative pronoun and on the article of the embedded DP. All nouns used in the test items have been attested to be 
used before age 3, according to our search of the German CHILDES corpora (MacWhinney 2000).
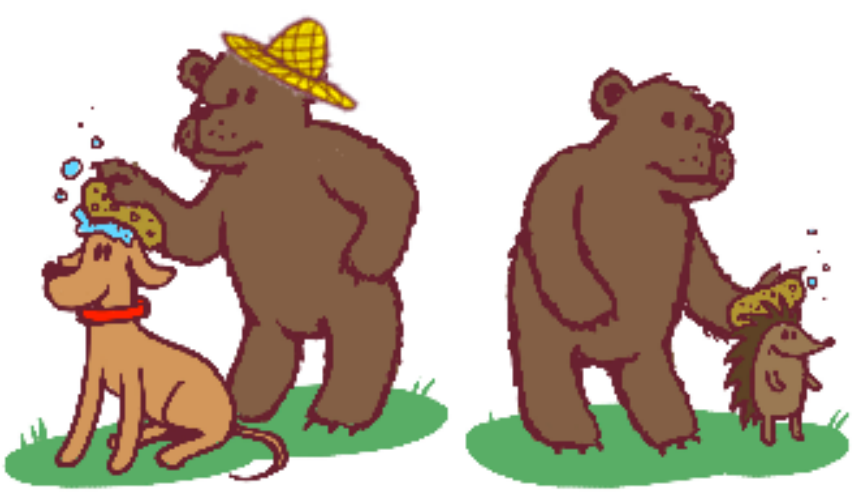

Figure 3. Picture paired with test item (6).

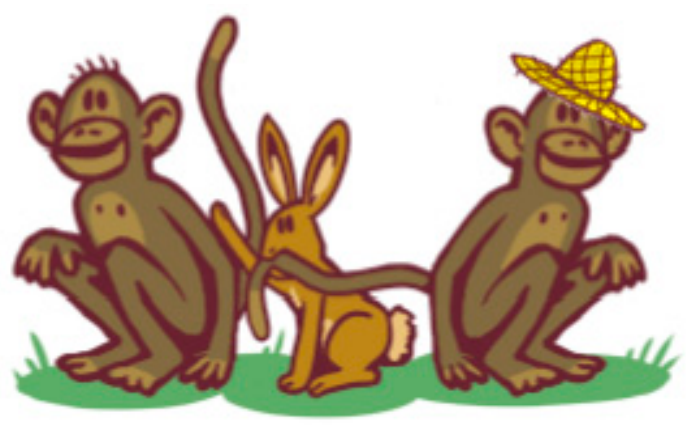

Figure 4. Picture paired with test item 7.

Participants were tested individually by a trained research assistant in a quiet room in their daycare. The test session started with a familiarization with the experimenter and the material. During this familiarization phase, the child was introduced to the frog-puppet Caru, who interacted with the child during the experimental session. The experimenter, the child, and the puppet sat on one side of a table on which a picture book and a box containing various hat-stickers were laid out in front of the child. The experiment was video-taped and audio-recorded for further analysis. Caru showed the child his favorite picture book of animals performing different actions, which he knew by heart (examples (67)). As part of a game, the experimenter then blindfolded Caru. This was done in order to reduce pointing responses and the use of the left/right one. The experimenter asked the child to choose one of the hats available as stickers and to place it on one of the two animals, which were the patients or the agents depending on the test condition: participants could choose to place the hat on one of the two agents in the agent-modifying condition and on one of the two patients in the patient-modifying condition. The child would put a hat on one of the animals, while Caru was already blindfolded. This was done to provide a natural context for asking the test question. Caru would describe by heart the scene in the book and ask the child "Which $\mathrm{X}$ is wearing the hat?" If the child did not react, Caru repeated the question. If necessary, the experimenter repeated the two warm-up items to ensure that the child understood the task. When the children gave responses such as "this one" or "the one on the left/right", the experimenter repeated the question, emphasizing that Caru could not see the pictures. After two prompts, the experimenter moved to the next test item. No response-contingent feedback was given. Adults were tested in one session; children were tested in two sessions, which lasted between 25 and 40 min each. 


\subsection{Results of Study 1}

A range of structures was produced by children and adults; here we focus on five types. (i) FULL RCs: grammatically and contextually appropriate SRCs or ORCs, describing the event in the picture correctly, (ii) SEMANTICALLY INAPPROPRIATE RCS: RCs that do not match the depicted event or did not answer the question, (iii) PARTICIPIAL STRUCTURES, (IV) WO-RCS, (V) PASSIVE RCS: SRCs introduced by a relative pronoun and with the predicate in passive voice. The remaining structures, labelled OTHERS, comprised main clauses, fragments, pointing, null reactions, productions of other types of subordinate clauses, and un-analyzable reactions. They were not included in any statistical analysis. For expository purposes, we report our findings in two tables. Table 2 reports the raw scores, percentages $(\%)$ and standard deviations $(\mathrm{N})$, of all the structures produced by our participants divided by age group in the agent-modifying condition. The results for the patient-modifying condition are illustrated in Table 3.

Table 2. Raw scores, percentages (\%), and standard deviations $(\mathrm{N})$ of the five structures produced in the agent-modifying condition for each age group.

\begin{tabular}{|c|c|c|c|c|c|}
\hline & Age 3 & Age 4 & Age 5 & Age 6 & Adults \\
\hline FULL RCS & $\begin{array}{c}165 \\
25.5 \% \\
(29.6)\end{array}$ & $\begin{array}{c}496 \\
66.7 \% \\
(34.2) \\
\end{array}$ & $\begin{array}{c}545 \\
73.3 \% \\
(28.4)\end{array}$ & $\begin{array}{c}480 \\
79.8 \% \\
(26.2)\end{array}$ & $\begin{array}{c}481 \\
88.9 \% \\
(16.3)\end{array}$ \\
\hline $\begin{array}{l}\text { SEMANT. } \\
\text { INAPPR. RCS }\end{array}$ & $\begin{array}{c}27 \\
4.2 \% \\
(8.9)\end{array}$ & $\begin{array}{c}51 \\
6.9 \% \\
(3.9)\end{array}$ & $\begin{array}{c}50 \\
6.7 \% \\
(20)\end{array}$ & $\begin{array}{c}40 \\
6.7 \% \\
(2.8)\end{array}$ & $\begin{array}{c}2 \\
0.4 \% \\
(1.3)\end{array}$ \\
\hline $\begin{array}{l}\text { PARTICIPIAL } \\
\text { STRUCTURES }\end{array}$ & $\begin{array}{l}- \\
- \\
-\end{array}$ & $\begin{array}{l}- \\
- \\
-\end{array}$ & $\begin{array}{l}- \\
- \\
-\end{array}$ & $\begin{array}{l}- \\
- \\
-\end{array}$ & $\begin{array}{c}6 \\
1.2 \% \\
(4.6)\end{array}$ \\
\hline Wo-RCs & $\begin{array}{c}18 \\
2.8 \% \\
(13.6)\end{array}$ & $\begin{array}{c}14 \\
1.9 \% \\
(10.5)\end{array}$ & $\begin{array}{c}4 \\
0.5 \% \\
(2.9)\end{array}$ & $\begin{array}{c}22 \\
3.7 \% \\
(13.5)\end{array}$ & $\begin{array}{c}15 \\
3 \% \\
(13.3)\end{array}$ \\
\hline PAssive RCs & $\begin{array}{l}- \\
- \\
-\end{array}$ & $\begin{array}{l}- \\
- \\
-\end{array}$ & $\begin{array}{l}- \\
- \\
-\end{array}$ & $\begin{array}{l}- \\
- \\
-\end{array}$ & $\begin{array}{l}- \\
- \\
-\end{array}$ \\
\hline OTHERS & $\begin{array}{c}438 \\
67.6 \% \\
(18.2)\end{array}$ & $\begin{array}{c}183 \\
24.6 \% \\
(16.7)\end{array}$ & $\begin{array}{c}145 \\
19.5 \% \\
(13.7)\end{array}$ & $\begin{array}{c}58 \\
9.7 \% \\
(4.3)\end{array}$ & $\begin{array}{l}- \\
- \\
-\end{array}$ \\
\hline TOTAL & 648 & 744 & 744 & 600 & 504 \\
\hline
\end{tabular}

Descriptively, FULL RCS were produced more frequently in the agent-modifying than in the patient-modifying condition by both children and adults; the proportion of FULL RCS in Table 2, i.e., SRCs, increased with age. SEMANTICALLY INAPPROPRIATE RCS occurred more frequently in the patient- than in the agent-modifying condition; they were almost exclusively produced by children. PARTICIPIAL STRUCTURES were produced very rarely in either condition and only by adults. Similarly, WO-RCS were not frequently produced with no discernable distinctions between conditions and age groups. Finally, PASSIVE-RCS were produced only in the patient-modifying context, as expected, and their production increased with age.

Data were analyzed using R ( R Core Team 2016), in combination with the lme4 package (Bates et al. 2015), and lsmeans (Lenth Russell 2016) to perform a series of analyses. In a first step we asked whether participants' production rates differed across structures, conditions, and age. We fitted participants' responses to a generalized mixed effects logistic regression model. Participants' productions were our dependent variable. As fixed factors, we posited the following variables: structure type (i.e., FULL RCS, SEMANTICALLY INAPPROPRIATE RCS, PARTICIPIAL STRUCTURES, WO-RCS, PASSIVE RCS), condition (agent-modifying vs. 
patient-modifying context), age (3-, 4-, 5-, 6-year-olds, adults), and four interactions, i.e., structure type ${ }^{*}$ condition, structure type ${ }^{*}$ age, age ${ }^{*}$ condition, structure type ${ }^{*}$ age ${ }^{*}$ condition. Patient-modifying context was the reference category for condition, 3-year-olds for the age factor, RCs for structure. The model was fitted using restricted maximum likelihood.

Table 3. Raw scores, percentages (\%), and standard deviations $(\mathrm{N})$ of the five structures produced in the patient-modifying condition for each age group.

\begin{tabular}{|c|c|c|c|c|c|}
\hline & Age 3 & Age 4 & Age 5 & Age 6 & Adults \\
\hline \multirow{3}{*}{ FULL RCS } & 32 & 61 & 76 & 65 & 13 \\
\hline & $4.9 \%$ & $8.2 \%$ & $10.2 \%$ & $10.8 \%$ & $2.6 \%$ \\
\hline & $(15.9)$ & $(22.9)$ & $(22.3 \%)$ & $(20.8)$ & $(9.4)$ \\
\hline \multirow{3}{*}{$\begin{array}{c}\text { SEMANT. } \\
\text { INAPPR. RCS }\end{array}$} & 139 & 382 & 226 & 173 & 3 \\
\hline & $21.4 \%$ & $51.3 \%$ & $30.4 \%$ & $28.8 \%$ & $0.6 \%$ \\
\hline & $(37.1)$ & $(30.2)$ & $(37.4)$ & $(35.1)$ & $(1.9)$ \\
\hline \multirow{3}{*}{$\begin{array}{l}\text { PARTICIPIAL } \\
\text { STRUCTURES }\end{array}$} & - & - & - & - & 21 \\
\hline & - & - & - & - & $5.4 \%$ \\
\hline & - & - & - & - & (16.3) \\
\hline \multirow{3}{*}{ Wo-RCs } & 13 & 16 & 9 & 36 & 23 \\
\hline & $2 \%$ & $2.1 \%$ & $1.2 \%$ & $6 \%$ & $4.6 \%$ \\
\hline & $(9.4)$ & $(9.7)$ & $(5.2)$ & $(15.8)$ & $(15.8)$ \\
\hline \multirow{3}{*}{ PASSIVE RCS } & 25 & 93 & 270 & 273 & 430 \\
\hline & $4.1 \%$ & $12.5 \%$ & $36.3 \%$ & $45.5 \%$ & $85.3 \%$ \\
\hline & (17.6) & $(29)$ & $(41.5)$ & (42.9) & $(26.1)$ \\
\hline \multirow{3}{*}{ OTHERS } & 439 & 192 & 163 & 53 & 14 \\
\hline & $67.7 \%$ & $25.8 \%$ & $21.9 \%$ & $8.8 \%$ & $2.8 \%$ \\
\hline & $(17.2)$ & $(11.5)$ & $(9.4)$ & $(5.5)$ & $(1.5)$ \\
\hline TOTAL & 648 & 744 & 744 & 600 & 504 \\
\hline
\end{tabular}

The model revealed significant effects of structure type and age, as well as of three interactions, structure type ${ }^{*}$ condition, structure type ${ }^{*}$ age, structure type ${ }^{*}$ age $e^{*}$ condition. Degrees of freedom, $F$-values and associated $p$-values for the model fits are reported in Table 4.

Table 4. Summary of the fixed factors in the mixed effects log-linear model for participants' productions.

\begin{tabular}{cccc}
\hline Effect & df & F & $p$ \\
\hline Structure & $4,134.15$ & 135.737 & $<0.001$ \\
Condition & $1,169.88$ & 0.684 & 0.409 \\
Age & $4,133.98$ & 21.526 & $<0.001$ \\
Structure*Condition & $4,140.68$ & 118.196 & $<0.001$ \\
Structure*Age & $16,134.15$ & 11.949 & $<0.001$ \\
Condition*Age & $4,169.94$ & 0.691 & 0.599 \\
Structure*Condition*Age & $16,140.70$ & 11.923 & $<0.001$ \\
\hline
\end{tabular}

(Full model summary $n=33,600$, REML $=-9291.8$ ).

On the basis of the effects revealed by the model, we proceeded with the additional analyses of our findings isolating structures and development. In Section 4.3.1, we focus on the structure type, addressing Q1. In Section 4.3.2, we zoom into the age factor and address Q2.

\subsubsection{Assessing Preference: Frequency of Structures within Each Age Group}

In order to determine which grammatical variants of nominal modification German children of different ages and adults prefer within a controlled experimental production 
task (Q1), we compared the production rates of the five structures within each age group. We focus on the factors "structure" and "condition".

Our model revealed a main effect of condition for FULL RCS (Estimate $=4.15, \mathrm{SE}=0.34$, Wald $Z=42.00, p<0.0001$ ), PASSIVE RCS (Estimate $=-4.6, \mathrm{SE}=0.99$, Wald $\mathrm{Z}=-4.6$, $p<0.0001$ ), and SEMANTICALLY INAPPROPRIATE RCS (Estimate $=-2.09$, SE $=0.33$, Wald $Z=-6.24, p<0.001$ ) in each age group (all coefficients for age fixed effects were significant in each group at $p<0.02$ ). While FULL RCS were more frequently produced in the agentmodifying context, both PASSIVE RCS and SEMANTICALLY INAPPROPRIATE RCS occurred significantly more frequent in the patient-modifying context. The effect of condition did not yield a significant effect for WO-RCs (Estimate $=0.5, \mathrm{SE}=0.55$, Wald $\mathrm{Z}=0.91, p=0.365$ ) and PARTICIPIAL STRUCTURES (Estimate $=0.06, \mathrm{SE}=0.44$, Wald $Z=-0.02, p=0.419$ ).

To investigate differences between the amounts of structures produced, we applied linear contrasts with Tukey correction within each age group. In the agent-modifying condition, the analyses revealed that FULL RCS were produced more frequently than SEMANTICALLY INAPPROPRIATE RCS in all age groups (Age 3: Estimate $=-0.05, \mathrm{SE}=0.013$, $t=-3.9, p<0.001 ;$ Age 4: Estimate $=-0.13, \mathrm{SE}=0.01, t=-9.14, p<0.001 ;$ Age 5: Estimate $=-0.16, \mathrm{SE}=0.01, t=-14.8, p<0.001$; Age 6: Estimate $=-0.2, \mathrm{SE}=0.01, t=-15.2$, $p<0.001$; Adults: Estimate $=-0.2, \mathrm{SE}=0.006, t=-28.9, p<0.001)$. FULL RCs were also more frequent than WO-RCS (Age 3: Estimate $=-0.05, \mathrm{SE}=0.013, t=-4.1, p<0.001$; Age 4: Estimate $=-0.13, \mathrm{SE}=0.014, t=-9.15, p<0.001$; Age 5: Estimate $=-0.2, \mathrm{SE}=0.01$, $t=-15.2, p<0.001$; Age 6: Estimate $=-0.17, \mathrm{SE}=0.01, t=-15.3, p<0.001$; Adults: Estimate $=-0.17, \mathrm{SE}=0.03, t=-14.8, p<0.001)$.

In the patient-modifying condition a different picture emerged. Post hoc comparisons with a Tukey correction demonstrated that at age 3 and 4 SEMANTICALLY INAPPROPRIATE RCS were produced significantly more frequently than FULL RCS (Age 3: Estimate $=-0.05 ; \mathrm{SE}=0.01 ; t=-3.9, p<0.001 ;$ Age 4: Estimate $=-0.13 ; \mathrm{SE}=0.014, t=-8.9$, $p<0.001$ ) as well as than PASSIVE RCS (Age 3: Estimate $=0.13$; $\mathrm{SE}=0.04, t=2.7, p=0.01$; Age 4: Estimate $=0.3, \mathrm{SE}=0.06, t=5.6, p<0.001)$. At ages 3 and 4 , no significant differences were found between the production rates of FULL RCS, PASSIVE RCS, and WO-RCS (all $p^{\prime}$ s $>0.1$ ). At age 5, 6, and in the adult group, PASSIVE RCS were produced significantly more frequently than FULL RCS (Age 5: Estimate $=-0.12$ SE $=0.01, t=-13.3, p<0.001$; Age 6: Estimate $=-0.17, \mathrm{SE}=0.01, t=-14.5, p=0.001$; Adults: Estimate $=-0.14 ; \mathrm{SE}$ $=0.035, t=-4.06, p<0.001)$. PASSIVE RCS also occurred significantly more often than SEMANTICALLY INAPPROPRIATE RCS in the adult group (Estimate $=-0.17$; $S E=0.02$, $t=-8.45, p<0.001)$. No significant differences were found between the production rates of PASSIVE RCS and SEMANTICALLY INAPPROPRIATE RCS at ages 5 and 6 (both $p^{\prime}$ s $>0.06$ ).

In short, our analyses show that, in the agent-modifying condition, FULL RCS were preferred by all age groups. In the patient-modifying condition, SEMANTICALLY INAPPROPRIATE RCS were preferred at age 3 and 4, while older children and adults preferred PASSIVE RCS.

Next, we conducted an individual analysis to detect to what extent the preferred structure within each age-group was also present at the individual level. We asked how many children within each age group aligned with the observed group preference and how many deviated from it. We define a structure as being preferred if it occured in more than half of the child's productions, namely in more than 12 items. The preference for FULL RCS found at the group level in the agent-modifying condition was also observed at the individual level, with the proportion of particpants showing this preference increasing with age: $14 / 27$ at age $3,25 / 31$ at age $4,29 / 31$ at age 5,22/25 at age 6 , and 20/21 adults preferred FULL RCs. In contrast, 25 out of the 135 participants, i.e., 24 children and 1 adult, exhibited a preference that differed from the group preference in the Agent-modifying condition. Several participants preferred responses coded as OTHERS (Age 3: 13/27 children; Age 4: 4/31; Age 6: 1/25), SEMANTICALly INAPPROPRIATE RCs (Age 4: 1/31; Age 5: 1/31; Age 6: 1/25), WO-RCs (Age 4: 1/31; Age 6: 1/25; Adults: 1/21). In the production of 1/31 
5-year-old child, the amount of FULL RCS was identical to the amount of SEMANTICALLY INAPPROPRIATE RCS.

In the patient-modifying condition, 10/27 three-year-olds and 20/31 four-year-olds preferred SEMANTICALLY INAPPROPRIATE RCS, thereby aligning with the respective trends at group-level. In total, 19/31 five-year-old children, 14/25 children aged 6, and $19 / 21$ adults aligned with their age group trend preferring PASSIVE RCs. Overall 53 out of the 135 participants exhibited a preference that differed from the group preference in the patient-modifying condition. While SEMANTICALLY INAPPROPRIATE RCS were preferred at the group level at age 3 and 4, some children preferred OTHERS (Age 3: 14/27 children; Age 4: 4/31) PASsIVE RCs (Age 3: 2/27; Age 4: 4/31), Full RCs (Age 4: 2/31), and wo-RCs (Age 3: 1/27; Age 4: 1/31). PASSIVE RCs were preferred by the 5-year-olds, the 6-year-olds and the adults at the group level; some speakers deviated from this group preference and preferred different structures: OTHERS (Age 6: 1/25), SEMANTICALLY INAPPROPRIATE RCS (Age 5: 10/31; Age 6: 8/25), Full RCs (Age 5: 2/31; Age 6: 1/25), and wo-RCs (Age 6: 1/25; Adults: $1 / 21$ ), and PARTICIPIAL STRUCTURES (Adults: $1 / 21$ ).

In short, the preference trends detected at the group level were generally present at the individual level as well. However, our data also revealed a certain degree of variation between speakers within each age group, especially detectable in the younger children and more noticable in the patient- than in the agent-modifying condition.

\subsubsection{Assessing the Developmental Path: Frequency of Structures Across Age Groups}

In the previous section, we established the structural preferences within each age group. Now we turn to the second research question $(\mathrm{Q} 2)$ of whether the preferred variants change in the course of acquisition. We examined each of the five structures produced by our participants across the five age groups. We focus on the effect of the "age" factor in the mixed effects logistic regression model.

Full RCs

Note that, in the agent-modifying condition, a FULL RCS refers to an SRC and, in the patient-modifying condition, to an ORC. In order to investigate the differences between age groups regarding the rate of FULL RCS, we collapsed the agent-modifying and the patient-modifying conditions and compared the age groups to each other, applying linear contrasts with Tukey correction. Table 5 reports a summary of the results of the post hoc comparisons.

Table 5. Summary of the age factor in the mixed effects logistic regression model for producing FULL RCS.

\begin{tabular}{ccccc}
\hline Groups & Estimate & SE & Wald Z & $p$ \\
\hline Age 3 vs. Age 4 & -2.52 & 0.43 & -5.88 & $<0.0001$ \\
Age 3 vs. Age 5 & -2.95 & 0.43 & -6.87 & $<0.0001$ \\
Age 3 vs. Age 6 & -3.30 & 0.45 & -7.31 & $<0.0001$ \\
Age 3 vs. Adults & -3.31 & 0.47 & -7.03 & $<0.0001$ \\
Age 4 vs. Age 5 & -0.43 & 0.40 & -1.08 & 0.817 \\
Age 4 vs. Age 6 & -0.78 & 0.42 & -1.86 & 0.341 \\
Age 4 vs. Adults & -0.79 & 0.44 & -1.79 & 0.378 \\
Age 5 vs. Age 6 & -0.35 & 0.42 & -0.84 & 0.919 \\
Age 5 vs. Adults & -0.36 & 0.44 & -0.82 & 0.924 \\
Age 6 vs. Adults & -0.01 & 0.46 & -0.02 & 1.000 \\
\hline
\end{tabular}

The performance of 3-year-olds on FULL RCs significantly differed from that of all other age groups. No significant differences in the rate of FULL RCs were found between all other age groups.

To see whether there were other differences regarding FULL ORCS that went undetected by this analysis, we explored which type of FULL ORCs children and adults produced. Two types were attested in our data: FULL ORCs with both the head noun and 
the subject being lexical nouns, as in (8a), and FULL ORCs with a pronominal RC head and a lexical subject $(8 b)$.

8. a. Der Affe den Der Hase beißt the.NOM donkey who.ACC the.NOM hare bites

"The monkey which the hare is biting."

b. Der den der Hase beißt the.NOM who.ACC the.NOM hare bites

"The one that the hare is biting."

Accordingly, we calculated the number of FULL ORCs with two nouns (8a) and with a pronoun and a noun (8b). Table 6 summarizes the results.

Table 6. Raw scores (N), percentages (\%) of FULL ORCS with two nouns or with noun and pronoun by age group.

\begin{tabular}{cccccc}
\hline \multirow{2}{*}{ Groups } & Total ORCs & \multicolumn{2}{c}{ Noun-Noun } & \multicolumn{2}{c}{ Pronoun-Noun } \\
\cline { 2 - 6 } & $\mathbf{N}$ & $\mathbf{N}$ & $\%$ & $\mathbf{N}$ & $\%$ \\
\hline Age 3 & 32 & 2 & 6.2 & 30 & 94 \\
Age 4 & 61 & 7 & 11.5 & 54 & 88.5 \\
Age 5 & 76 & 0 & 0 & 76 & 100 \\
Age 6 & 65 & 4 & 6 & 61 & 94 \\
Adults & 13 & 8 & 62 & 5 & 38 \\
\hline
\end{tabular}

Table 6 shows that the great majority of FULL ORCs produced by children contains a pronominal head and a lexical DP subject, while adults' production is more balanced between the two types of ORCs. Because of the low overall frequencies, all child groups were collapsed for the statistical analysis. An ANOVA revealed that FULL ORCs occurred significantly more often with Pronoun-Noun than with Noun-Noun in the children groups $(\mathrm{SE}=1.1, t=-4.7, p<0.001)$, but not in the adult group $(\mathrm{SE}=4.9, t=0.3, p=0.99)$.

Semantically inappropriate productions: modification of the wrong noun

To investigate the differences between the groups again we applied linear contrasts with Tukey correction. Children in all age groups produced significantly more SEMANTICALLY INAPPROPRIATE RCS than adults, while the child groups did not differ significantly from each other. Table 7 reports a summary of the results of the post hoc comparisons.

Table 7. Summary of the age factor in the mixed effects logistic regression model for producing SEMANTICALLY INAPPROPRIATE RCS.

\begin{tabular}{ccccc}
\hline Groups & Estimate & SE & Wald Z & $p$ \\
\hline Age 3 vs. Age 4 & -1.55 & 0.61 & -2.55 & 0.081 \\
Age 3 vs. Age 5 & -0.99 & 0.61 & -1.6 & 0.488 \\
Age 3 vs. Age 6 & -0.55 & 0.65 & -0.84 & 0.917 \\
Age 3 vs. Adults & 3.76 & 1.06 & 3.537 & 0.003 \\
Age 4 vs. Age 5 & 0.56 & 0.55 & 1.02 & 0.847 \\
Age 4 vs. Age 6 & 1.004 & 0.59 & 1.68 & 0.444 \\
Age 4 vs. Adults & 5.316 & 1.04 & 5.09 & $<0.0001$ \\
Age 5 vs. Age 6 & 0.44 & 0.59 & 0.736 & 0.948 \\
Age 5 vs. Adults & 4.75 & 1.04 & 4.548 & 0.0001 \\
Age 6 vs. Adults & 4.31 & 1.06 & 4.046 & 0.0005 \\
\hline
\end{tabular}

\section{Wo-RCs}

There was no significant difference depending on age (all coefficients for age fixed effects $p>0.6)$. The amount of WO-RCs production was very low and remained stable across all ages. An individual analysis revealed that overall only 6/133 children (Age 3: 1; Age 4: 1; Age 5: 2; Age 6: 2) and 1/21 adults produced WO-RCs. Resumption in WO-RCS was not attested in our data. 


\section{Participial structures}

The number of PARTICIPIAL STRUCTURES in both conditions, agent- and patientmodifying, was very low overall. They were produced by adults only: 6 responses in the agent condition (1.2\%) and 21 responses in the patient condition (5.4\%) (see Tables 2 and 3), produced by 2 adults, who used them quite consistently.

Passive RCs

To investigate the differences in the rate of PASSIVE RC production between the age groups, we compared the age groups to each other, again applying linear contrasts with Tukey correction. Table 8 summarizes the results of the statistical analysis.

Table 8. Summary of the age factor in the mixed effects logistic regression model for PASSIVE RCS.

\begin{tabular}{ccccc}
\hline Groups & Estimate & SE & Wald Z & $p$ \\
\hline Age 3 vs. Age 4 & -0.81 & 1.25 & -0.65 & 0.967 \\
Age 3 vs. Age 5 & -5.44 & 1.33 & -4.07 & 0.0004 \\
Age 3 vs. Age 6 & -6.05 & 1.40 & -4.32 & 0.0002 \\
Age 3 vs. Adults & -10.77 & 1.44 & -7.45 & $<0.0001$ \\
Age 4 vs. Age 5 & -4.62 & 1.26 & -3.94 & 0.002 \\
Age 4 vs. Age 6 & -5.24 & 1.33 & -3.94 & 0.0008 \\
Age 4 vs. Adults & -9.96 & 1.40 & -7.11 & $<0.0001$ \\
Age 5 vs. Age 6 & -0.62 & 1.40 & -0.44 & 0.992 \\
Age 5 vs. Adults & -5.34 & 1.43 & -3.75 & 0.002 \\
Age 6 vs. Adults & -4.72 & 1.48 & -3.19 & 0.012 \\
\hline
\end{tabular}

Children in all age groups significantly differed from adults in the likelihood of producing PASSIVE RCS. Among the child groups, there was no significant difference between 3- and 4-year-olds and no significant difference between 5- and 6-year-olds. 3year-olds and 4-year-olds differed from both 5- and 6-year-olds, indicating that use of PASSIVE RCS was higher in the two older groups than in the younger two groups.

PASSIVE RCS constituted the most frequent structure from age 5 onwards and the second frequent one at age 4 (see Table 3). Passive RCs were used, once or repeatedly, by $6 / 27$ children at age 3 , by $8 / 31$ children at age 4 , by $18 / 31$ children at age 5 , by $17 / 25$ children at age 6 , and by all 21 adults. In a next step, we analyzed the formal properties defining passive in German: (i) the type of auxiliary; (ii) the lexicalization of the agent; (iii) the position of the agent-phrase in the RC (see also Section 5.1).

As for (i), children at all ages used almost exclusively passive RCs with the auxiliary werden "to become", expressing eventive passive. One 5-year-old used two PASSIVE RCS with the auxiliary sein "to be", signaling stative passive (Der der von dem Löwen gebissen ist "the one that is bitten by the lion"; Der der von dem Tiiiger gewaschen ist "the one that is washed by the tiger"). Adults nearly always used the werden passive, except for two cases of bekommen "to get" passive. These results suggest that, already at age 3, children are adult-like in using the eventive passive in these RCS.

We turn to (ii), the lexicalization of the agent in the RC, next. Recall that our design depicted two different scenarios (see Section 4.2): a "contrasting action" scenario with only one agent performing two different actions (half of the test items) and an "agent contrasting" scenario with two different agents performing the same action (the other half of the test items) (see Table A1 in Appendix A for the scores of PASSIVE RCs in the two contexts). In the "contrasting actions" scenario, the agent does not need to be lexicalized, since the referent can be identified by the type of action he performs, but in the "contrasting participants" scenario, it is mandatory: the referent can only be identified if the agent performing the action is mentioned. Accordingly, we calculated how many LONGPASSIVES, i.e., PASSIVE RCS with a lexicalized agent, were produced in the two contexts in each age group. Note that the lexicalized agent was always expressed by a von + DP. Table 9 summarizes the rate of LONG-PASSIVES produced in the two contexts in each age group. 
Table 9. Raw scores (N), percentages (\%), and standard deviations (SD) of LONG-PASSIVES in the contrasting actions and contrasting agent contexts for each age group (out of all passive structures).

\begin{tabular}{ccccccccc}
\hline \multirow{2}{*}{ Groups } & \multicolumn{3}{c}{ Contrasting Actions } & \multicolumn{5}{c}{ Contrasting Agents } \\
\cline { 2 - 9 } & Total & $\mathbf{N}$ & $\mathbf{\%}$ & SD & Total & $\mathbf{N}$ & $\%$ & SD \\
\hline Age 3 & 13 & 8 & 61.5 & 1.5 & 12 & 12 & 100 & 2.1 \\
Age 4 & 44 & 8 & 18.2 & 1.1 & 49 & 47 & 95.9 & 3.5 \\
Age 5 & 146 & 33 & 22.6 & 2.3 & 124 & 122 & 98.4 & 4.6 \\
Age 6 & 148 & 24 & 16.2 & 2.6 & 125 & 121 & 96.8 & 4.8 \\
Adults & 207 & 141 & 68.1 & 4.4 & 223 & 223 & 100 & 3.0 \\
\hline
\end{tabular}

Adults produced LONG-PASSIVES in both contexts. Children produced SHORT- and some LONG-PASSIVES in the "contrasting actions" context, but almost exclusively LONGPASSIVES in the "contrasting agents" context. Only in eight instances in the "contrasting agents" context did the PASSIVE RC contain no agent phrase; an individual analysis revealed that these deviant productions were produced by one 4-year-old, one 5-year-old, and one 6-year-old each.

As a third aspect (iii), we considered the position of the von-phrase within the RC. After all, it may be that, despite the high number of LONG-PASSIVES, children's von-phrases were not in target-like position, i.e., properly integrated within the clause. Three different wordorders were found, based on the position of the von-phrase (PP) in relation to the participle (Part) and the auxiliary (Aux). The target word order PP-Part-Aux (der von dem Hasen gebissen wird "who is bitten by the hare") was by far the most frequent one across all age groups (Age 3: 23/25, Age 4: 82/93, Age 5: 252/270, Age 6: 263/273, Adults: 424/430). The order Part-Aux-PP, where the PP is extraposed-maybe as a kind of afterthought-(der gebissen wird von dem Hasen "who is bitten by the hare") was found rarely in both children and adults (Age 3: 2/25, Age 4: 11/93, Age 5: 15/270, Age 6: 10/273, Adults: 6/430). The order Part-PP-Aux (der gebissen von dem Hasen wird) was used only in three PASSIVE RCS by one 5-year-old. In summary, children and adults pattern alike with respect to all three formal properties of passives in PASSIVE RCS: use of the auxiliary werden, lexicalization of the agent if required, and word order of von-PP, participle and auxiliary.

\subsection{Discussion}

Preference of the grammatical variants within age groups

Concerning Question 1, asking which grammatical variants of nominal modification German children of different ages and adults prefer within a controlled experimental production task, our elicited production data revealed that adults and children across all ages opted for different structures, depending on whether the modified participant was the agent or the patient of the action. When prompted to modify the agent of the action, adults and children at all ages most frequently produced FULL RCS. This result is in line corpus studies who report a high rate of SRCs (Fabricius-Hansen 2010; Lübbe and Rapp 2011; Bader and Koukoulioti 2018). When prompted to modify the patient of the action, PASSIVE RCS and, in the child groups, SEMANTICALLY INAPPROPRIATE RCS were produced most frequently; both findings are clearly not in line with the expectations derived from the frequency account. At the same time, the low frequency of FULL ORCs attested in our experimental setting involving two animate participants confirms corpus studies, which found FULL ORCs to be infrequent, and supports a frequency-based explanation.

In contrast to the previous findings (Adani et al. 2012; Yatsushiro and Sauerland 2019), WO-RCS were not a frequent response in either the agent- or patient-modifying condition. This difference may be a result of the regional variant of German spoken in the area where participants were recruited: Northern Germany in their case, where WO-RCs have been documented, and XX in our case, where WO-RCs are not common (Fleischer 2004; Brandner and Bräuning 2013). Accordingly, our finding is in line with the frequency reported in the relevant corpus studies (Hirschberg et al. 2014) and is expected under the frequency 
account, given that, in the area where we recruited our participants, WO-RCs are indeed rarely found.

In line with the frequencies reported in corpus studies, PARTICIPIAL STRUCTURES were almost absent, with only two adults producing them, albeit quite consistently. This individual variation would also be consistent with the frequency account.

Finally, our individual analysis revealed that the clear preferences for a grammatical variant at the group level was supplemented with a certain degree of variation between speakers in each age group, which was different for different ages and condition. Adults behaved very consistently, all but one preferring full SRCs in the agent context and all but two opting for passive SRCs in the patient-modifying context. Individual variation was especially noticeable in the younger groups and for the patient-modifying context. Between the ages of 3 and 6, children are still in the process of discovering and mastering the several grammatical variants that exist in German. So, they may weigh different aspects of this acquisition puzzle differently and develop different strategies, when in need of deciding on a grammatical variant. Some may give up on the meaning side, opting for SEMANTICALLY INAPPROPRIATE RCS, other may give up on subordination, opting for main clauses (e.g., see, Fritzenschaft et al. 1990). ${ }^{5}$ Note that this account begs the question of whether these choices are driven by the same factor or by different ones and whether corpus frequency can account for this individual variation. We return to this point in the final discussion.

Frequency of structures across age

Turning to Question 2, of whether the preferred options change in the course of acquisition, we found that children and adults showed pronounced differences as well as similarities. Note first that WO-RCS and PARTICIPIAL STRUCTURES were very infrequent in both conditions (agent- and patient-modifying) in all age groups, so we will not address their development here.

In the agent-modifying condition, children and adults overall preferred FULL SRCS, with statistical analyses revealing a developmental step from age 3 to age 4: three-year-old children produced fewer FULL SRCs than all the other age groups, whose production rates did not differ anymore from that of the adults. This finding agrees with previous acquisition studies on German and other languages showing that children master SRCs at the age of 4 (Rothweiler 1993; Diessel and Tomasello 2005, a.o.).

In the patient-modifying condition, our data revealed several differences across age groups. First, children at all ages, as well as adults, produced very few FULL ORCS, with the type of ORC being markedly different: whereas adults produced FULL ORCS with two lexical nouns, RC head and subject DP, children at all ages most frequently produced FULL ORCs with a pronominal RC and a lexical subject DP. Assuming that frequency shapes language acquisition, this difference is difficult to explain under the frequency account.

Second, while adults preferred PASSIVE RCS in the patient-modifying context, children's responses differed according to age: at ages 3 and 4, the most frequent structures were SEMANTICALLY INAPPROPRIATE RCS, whereas at ages 5 and 6 , they were PASSIVE RCS, just as in the adult group. In addition, the rate of PASSIVE RCS increased significantly with age, with children at age 6 still producing significantly fewer PASSIVE RCS than the adults. PASSIVE RCS were used already by the three-year-olds, which confirms previous studies reporting early production of passives (Abbot-Smith and Behrens 2006). No qualitative differences between adults and children emerged regarding the formal properties of PASSIVE RCS: the passive structures contained an eventive passive, the agent-phrase was lexicalized when required, and the word order of participle and agent-phrase signaled syntactic integration. These data confirm the findings on long passives in 5-year-old German children by Yatsushiro and Sauerland (2019) for younger children. Our results contrast with the finding in Mills (1985), however, according to which children up to the age of 5 produce stative passives and short passives. Our detailed analysis of PASSIVE RCS

5 Longitudinal studies would be beneficial for uncovering how the structural preferences develop within a child. 
demonstrated that the syntactic properties of PASSIVE RCS were in place from the age of 3 onwards. This result does not follow from the corpus frequencies, in particular from frequencies derived from child-directed speech, which showed passives to be infrequent.

Summary

Study 1 showed that children's and adults' patterns were alike in several respects: they most frequently produced FULL SRCS in the agent-modifying condition, and they frequently produced PASSIVE RCS in the patient-modifying condition. In addition, the formal proprieties of the PASSIVE RCS were the same across all age groups. While the production of FULL SRCS was expected on the basis of the previous acquisition studies, the fact that children produced so many PASSIVE RCS is surprising given that studies on child-directed speech found passive to be very rare. Accordingly, in Study 2, we examine whether the child PASSIVE RCS elicited in the experimental task reflect the frequency of PASSIVE RCS in children's ambient language; this has, to our knowledge, not been examined before.

\section{Study 2: Passives and Passive Subject RCs in Child-Directed Speech}

Addressing the issue of the frequency of passives and PASSIVE RCs in children's ambient language, Study 2 asks how frequently these structures occur in child-directed speech and which formal properties these PASSIVE RCs exhibit. The data were drawn from the spontaneous child-directed speech corpus of Leo's mother, available in the CHILDES database (MacWhinney 2000; Abbot-Smith and Behrens 2006) ${ }^{6}$. As a high-density data base, the Leo corpus is especially suitable for arriving at reliable frequency estimates for structures that may occur with relatively low frequency (Abbot-Smith and Behrens 2006). The period in which Leo and his mother were recorded covers the age range from 1;11 to 4;11, i.e., exactly the age at which RCs are known occur in children's speech.

\subsection{Results of the Corpus Investigation}

The passives produced in Study 1 by children and adults all exhibited the auxiliary werden "become". Therefore, all tokens containing a form of werden (werde/ werden/werdet/ wird/ wirst) were extracted from the productions of Leo's mother using the commands: combo $+\mathrm{t}^{*} \mathrm{MUT}+\mathrm{s}^{\prime \prime}$ werd $^{* \prime *}$ *.cha, $+\mathrm{t}^{*} \mathrm{MUT}+\mathrm{s}^{\prime \prime}$ wird" *.cha; $+\mathrm{t}^{*} \mathrm{MUT}+\mathrm{s}^{\prime \prime}$ wirst" $^{\prime *}$.cha. The 2527 occurrences were manually coded according to the grammatical function of the verb werden: passive auxiliary as in (9), future auxiliary, or lexical verb; utterances that could not be classified because of missing lexical material were coded as ambiguous.

9. a. Die müssen ja auch verbraucht werden

These must PART also used become

"These must also be used."

(011127.cha line 1561)

Out of the total number of 2527 werden occurrences, 690 cases contained werden as a passive auxiliary (27.3\%), 975 occurrences contained werden as the future auxiliary (38.6\%), 774 contained werden as a lexical verb (30.6\%), and 88 cases were ambiguous (3.5\%). Our analyses were based on the 690 utterances in which the mother produced werden as the passive auxiliary.

First, we wanted to know how frequently werden-passives occur in Leo's mother speech. To this end, we derived the raw number of utterances with the werden-passive for each monthly recording and calculated the proportion based on all utterances of the mother. The total of utterances produced by Leo's mother was calculated with an MLU analysis conducted on the \%mor line (https:/ / talkbank.org/morgrams / (accessed on 29 October 2019)). The command "mlu $+\mathrm{t}^{*} \mathrm{MUT}$ *.cha" was run in the CLAN program, which yielded the number of utterances produced in each file. Grouping the files by month and summing up the number of utterances in each file, we obtained the total of utterances produced

6 Available online: https://childes.talkbank.org/access/German/Leo (first accessed on 29 October 2019; last accessed on 8 December 2020). 
per month. Table 10 illustrates the frequency of the utterances containing werden-passives, compared to the total of utterances produced by Leo's mother.

Table 10. Number of werden-passives (raw N, \%) compared to the total number of utterances produced by Leo's mother.

\begin{tabular}{|c|c|c|c|}
\hline Child Age (y;m) & $\begin{array}{c}\text { Number of } \\
\text { Werden-Passive in } \\
\text { the Mother's Speech }\end{array}$ & $\begin{array}{c}\text { Total N of Utterances } \\
\text { Leo's Mother }\end{array}$ & $\begin{array}{c}\text { \% of Werden-Passive } \\
\text { in the Mother's } \\
\text { Speech }\end{array}$ \\
\hline $1 ; 11$ & 1 & 2278 & 0.04 \\
\hline $2 ; 00$ & 40 & 10,961 & 0.36 \\
\hline $2 ; 1$ & 3 & 6685 & 0.04 \\
\hline $2 ; 2$ & 24 & 7936 & 0.30 \\
\hline $2 ; 3$ & 15 & 7178 & 0.21 \\
\hline $2 ; 4$ & 15 & 10,738 & 0.14 \\
\hline $2 ; 5$ & 48 & 10,021 & 0.48 \\
\hline $2 ; 6$ & 36 & 4689 & 0.77 \\
\hline $2 ; 7$ & 23 & 7801 & 0.29 \\
\hline $2 ; 8$ & 70 & 8446 & 0.83 \\
\hline $2 ; 9$ & 51 & 6438 & 0.79 \\
\hline $2 ; 10$ & 24 & 7461 & 0.32 \\
\hline $2 ; 11$ & 38 & 7962 & 0.48 \\
\hline $3 ; 0$ & 8 & 2473 & 0.32 \\
\hline $3 ; 1$ & 8 & 2258 & 0.35 \\
\hline $3 ; 2$ & 6 & 2004 & 0.30 \\
\hline $3 ; 3$ & 7 & 1513 & 0.46 \\
\hline $3 ; 4$ & 7 & 1978 & 0.35 \\
\hline $3 ; 5$ & 15 & 3930 & 0.38 \\
\hline $3 ; 6$ & 12 & 2376 & 0.51 \\
\hline $3 ; 7$ & 38 & 2918 & 1.30 \\
\hline $3 ; 8$ & 7 & 1883 & 0.37 \\
\hline $3 ; 9$ & 3 & 1553 & 0.19 \\
\hline $3 ; 10$ & 7 & 2385 & 0.29 \\
\hline $3 ; 11$ & 20 & 3007 & 0.67 \\
\hline $4 ; 0$ & 16 & 2875 & 0.56 \\
\hline $4 ; 1$ & 14 & 3279 & 0.43 \\
\hline $4 ; 2$ & 13 & 3236 & 0.40 \\
\hline $4 ; 3$ & 21 & 3119 & 0.67 \\
\hline $4 ; 4$ & 9 & 2756 & 0.33 \\
\hline $4 ; 5$ & 13 & 2582 & 0.50 \\
\hline $4 ; 6$ & 10 & 2627 & 0.38 \\
\hline $4 ; 7$ & 22 & 3025 & 0.73 \\
\hline $4 ; 8$ & 14 & 2794 & 0.50 \\
\hline $4 ; 9$ & 16 & 2492 & 0.64 \\
\hline $4 ; 10$ & 9 & 2032 & 0.44 \\
\hline $4 ; 11$ & 8 & 3099 & 0.26 \\
\hline
\end{tabular}

The number of utterances containing werden-passives was very low, accounting for only $0.44 \%$ of mother's utterances. Statistical analyses revealed that the rates of werdenpassive productions did not significantly differ across years (Wilcoxon related samples, $\mathrm{Z}=6, p=0.25$ ).

In a next step, each utterance was manually coded for the following properties: (i) the syntactic environment in which the passive appeared, i.e., in a RC or not and if so, in a PASSIVE RC or not; (ii) the presence/absence of an agent-like participant, i.e., LONG vs. SHORT PASSIVES, and (iii) the position of the agent phrase with respect to the participle and the auxiliary. These properties allowed us to closely compare the input a child is exposed to with the productions elicited in Study 1.

As for property (i), of the 690 utterances containing werden-passives only 30 were RCs $(4.3 \%)$, most of them subject RCs (24/30) modifying an agent. The range of PASSIVE 
RCs produced varied between 0 and 3 per month, compared to the mother's total number of utterances that ranged between 2278 and 10,961 utterances per month (see Table A2 in Appendix A for the detailed information). We next compared the frequency of PASSIVE RCs against the frequency of other competing structures in the patient-modifying context. Since WO-RCs were absent in Leo's caregivers' speech, ${ }^{7}$ the frequency of PASSIVE RCs was compared with that of ORCs in the child's input reported in Brandt et al. (2008, p. 332). Brandt et al. (2008) analyzed five different periods: when Leo was 2;0, 2;7, $3 ; 2,3 ; 9$, and 4;10. Searching the corresponding files for the RCs produced by the adults, the authors extracted 330 RCs, of which 119 were ORCs. We selected the same age periods and the same files and found four occurrences of PASSIVE RCs (see Table A2 in Appendix A for the PASSIVE RCs occurrences in the five periods).

Regarding the second property, i.e., the presence/absence of a lexically realized agent phrase, 684 of the 690 sentences with werden-passives were analyzed further; six utterances had to be excluded because of ambiguity regarding the agent phrase. Depending on the lexical predicate, many different types of agent-like phrases were produced by Leo's mother, headed by von "by" (18/684), an "at" (1/684), auf "from" (2/684), bei "from" (1/684), durch "to" (3/684), in "in" (3/684), mit "with" (10/684), and über "above" (1/684). Note that the details of the syntactic analysis of these PPs are still a matter of debate. Specifically, it is open whether only von PPs encode the agent and the other PPs encode some kind of location (see Bruening 2013; Alexiadou and Schäfer 2013). In order to detect possible corpus frequency effects that may show up only for the broader PP category and not for von PPs, we included in our calculation all types of agent-like PPs mentioned above. Remarkably, 645 out of the 684 passive structures $(94.3 \%)$ did not contain a lexicalized agent PP. The remaining 39 LONG PASSIVES (5.7\%) were further analyzed regarding the position of the PP in relation to the participle and the auxiliary. Agent-like PPs occurred mostly in the middle-field $(n=29)$, and were only rarely extraposed $(n=7)$ or sentence-initially $(n=3$, in yes/no-questions).

Finally, looking at passives in SRCs, the picture is similar to the picture in passive structures in general: 20 out of 24 PASSIVE RCs (83.3\%) were produced without a lexicalized agent phrase. That is, in a corpus of child-directed speech, containing a total of 160,788 utterances, only four PASSIVE RCs contained a PP encoding an agent-like participant (von: 2 , in: 1 , mit: 1 ), corresponding to just $0.003 \%$ of the child's input.

\subsection{Study 2: Discussion of the Results}

Study 2 investigated the frequency and the formal properties of passives in childdirected speech to uncover in how far the frequency and the properties of child PASSIVE RCS elicited in Study 1 reflect the frequency and the formal properties of PASSIVE RCS in children's ambient language. We selected a high-density corpus which enabled us to determine a reliable estimate of the frequency of passive and more precisely of PASSIVE RCS in a child's input. We found that passive structures in general, and PASSIVE RCS in particular, were almost absent in the child-directed speech of Leo's mother, both compared to the total number of utterances and compared to the number of ORCs. This result is in line with previous corpus studies on adults' natural speech (Abbot-Smith and Behrens 2006; Zombolou and Alexiadou 2015), but crucially differs from our experimental findings in Study 1 for adults. Likewise, our analysis revealed that the great majority of passive utterances in child-directed speech did not contain a lexicalized agent-phrase, which is in line with the findings in Bader and Koukoulioti (2018), but again differs from the results in Study 1. The results from Study 2 and Study 1 converge regarding the word order attested for the agent-phrase and the verbal elements: in child-directed speech, the agent PP was most frequently placed in the middle field, signaling syntactic integration into the host clause, just as with the word order found in Study 1. Note that these conflicting results

7 All adult utterances containing wo "where" were either interrogative clauses, free RCs or RCs with a locative meaning. We leave for future research the investigation of participle structures in child-directed speech. 
are central to the question of whether language use can actually predict the structures produced in experimental settings. We discuss this pattern of results below.

\section{General Discussion and Implications}

Speakers typically have more than one way of getting their message across. As a case in point, when speakers want to identify the agent or the patient of an action, various structures will fulfill this conversational goal to the same degree. The essential question is which principle(s) guide the adult speaker's choice and whether the same principle(s) determine children's acquisition path. This paper contributes to this issue by examining whether frequency may be such a principle.

Frequency shapes language use and acquisition: our operationalization

Several studies have argued, specifically, that frequency affects language by shaping adults' language use and language acquisition. The more frequently a structure occurs, the more easily it will be activated or processed in an adult speaker's mental grammar. Likewise, more frequent constructions are acquired earlier and are produced at a higher rate by children than less frequent constructions. Given that young children, and even newborns, are sensitive to distributional regularities they are exposed to, it seems very likely that they are attuned to frequency effects.

At the same time, children are well-known for producing structures that are not consistent with the target-grammar, arguably constrained by universal grammar (Thornton 1990; Schulz and Tracy 2018), for quite some time; this is difficult to reconcile with a pure frequency account. Similarly, adults have been reported to produce specific structures in experimentally controlled contexts that are very infrequent in spontaneous speech (Belletti and Chesi 2014), which raises the question of how and why these infrequent structures were activated.

A reliable estimate of the frequency of the relevant structures is central for probing its role. Following Roland et al. (2007), we took the estimates of actual language use derived from corpus studies as a good proxy for the frequency of a given structure in adult speech. In addition, we took the estimates derived from corpus studies on child-directed speech to be a reliable proxy for the frequency of a structure in children's input. As discussed in Section 2.3, different estimates of the same structure have been proposed in corpus studies, varying with the type of corpus and the frequency measure employed. We compared the (sometimes contradictory) corpora findings with our findings. Study 1 addressed the aspects of adult use and child acquisition with an elicited production task, which provided equal opportunities to modify the agent and the patient of an action. Based on a longitudinal corpus of child-directed speech, Study 2 looked more closely into the frequency and the formal properties of passive structures and passive RCs, which turned out to be very frequently used in Study 1. In the following section, we discuss three general observations drawn from our studies.

Frequency of noun modifying structures in corpora and (the problem of) how to count

When looking at the frequency of structures across the two modification contexts, the problem arises of determining what to compare, i.e., to establish which frequency the speakers and language learners are sensitive to, as argued in Section 3.3. It may be total frequency of structures $A$ and $B$ (e.g., determined on the basis of all structures A, B, C, D, and $\mathrm{E}$, or all structures modifying a noun $\mathrm{A}, \mathrm{B}, \mathrm{C}$ ) and/or relative frequency of $\mathrm{A}$ and $\mathrm{B}$ (i.e., compared to the total of $\mathrm{A}$ and $\mathrm{B}$ ) that play a role. In our view, both notions of frequency leave unaddressed the fact that specific discourse situations may per se occur at very different rates. More specifically, we reasoned that the opportunity to produce SRCs and ORCs may differ, because the need to modify the agent and the need to modify the patient of an action may not occur at the same rate; this would result in different frequencies of SRCs and ORCs for conversational needs. The experimental design of Study 1 avoided this potential artefact by providing equal opportunities to modify agents and patients of an action. Our results did not single out one structure that was most frequently produced in absolute terms, for either children or adults. The most frequent structure was different 
for agent- and patient-modifying contexts, suggesting that the absolute frequency of a given structure may not be decisive in determining adult speakers' choices and language acquisition order. Speakers seem to be sensitive to subtler measures of frequency, which are calculated according to situational contexts (agent- vs. patient-modifying context) (see also Roland et al. 2007). Accordingly, we suggest that, when modeling the frequency of a given structure, any probabilistic theory of language production and acquisition needs to take into consideration that the likelihood to use particular structures is dictated by discourse needs.

Frequency of structures and the problem of what counts as a structure

When prompted to modify the agent of an action, adults and children at all ages most frequently produced SRCs. This result confirms German corpus studies, which reported SRCs to be, overall, the most frequent type of RC, and acquisition studies showing SRCs to be the first clausal nominal modification structure produced by children. From this, we may conclude that the frequency of SRCs determines its repeated use in a specific context and its early acquisition. However, we may also probe further and ask whether this conclusion only holds if the type of SRC found in corpora is the same as the SRC type used in Study 1. This question turns out to be crucial: the SRCs found in the corpora mostly contain an intransitive predicate or a copula, whereas the RCs in Study 1, due to our experimental design involving transitive events with two animate participants, all contained a transitive predicate. Put differently, how can the frequency of SRCs containing intransitive or copular predicates prompt the early and frequent use of SRCs with transitive predicates? In our view, we have to assume that adult speakers and children are sensitive to frequency measures computed based on structures as abstract objects, detached from the actual realizations, if we wish to maintain the role of frequency.

When prompted to modify the patient of an action, adults and children very rarely produced ORCs. As in the case of agent modification, an evaluation of these findings in terms of corpus frequency is not straight-forward. Overall, German corpus studies found ORCs to be rare but, among all RCs with a transitive predicate, to be more frequent than transitive SRCs. The ORCs attested in corpora are most often embedded by a lexical inanimate RC head and contain a pronominal animate subject, which is in contrast to the two animate nouns required by our experimental design in Study 1. Applying the same reasoning as in the case of SRCs, we would expect the relatively frequent type of ORCs in corpora such as the house that she bought to promote use of ORCs such as the monkey that the rabbit/it strokes, but clearly, this is not what we found. If we, nevertheless, wish to maintain a role of frequency for ORCs, we need to stipulate that adult speakers and children are sensitive to frequency measures computed based on subtypes of ORCs considering properties such as animacy. Accordingly, the notion of frequency that could account for our findings on ORCs is different from the one at play for SRCs.

As for the use of lexical nouns or pronouns in ORCs, adults produced both variants, two nouns or a pronoun and a noun, whereas children used mostly a pronominal RC head and a lexical noun subject. These results, together with previous corpus acquisition findings, suggest that children's first ORCs differ from the adult variants in a principled fashion. These differences are not predicted by frequency but can be explained with languageinternal factors: syntactic considerations dictate that the RC head and the subject DP in the child's grammar avoid the same lexical specification. Independent of their position, one DP needs to be a pronoun and the other a lexical noun, which can be expressed in terms of different syntactic features (e.g., via relativized minimality, see Friedmann et al. 2009; Belletti et al. 2012).

Given our findings on SRCs and ORCs, an important implication emerges for a definition of "structure" and its application in language acquisition. Frequency accounts propose that linguistic structures are organized in a hierarchically ordered network ranging from lexicalized constructions, i.e., concrete tokens of experience that are memorized (Bybee 2006), to highly abstract representations at the top (Diessel 2009). Under these approaches, children are assumed to first acquire the structures that match the concrete input-tokens 
and to gradually learn more schematic representations. In contrast, our results suggest that lexicalized constructions may not have an explanatory role in children's acquisition of RCs. Both in the case of SRCs and of the few elicited ORCs, we see that the children's acquisition order of structures relies on the notion of "structure" as an abstract object associated with (sometimes refined) syntactic considerations. Our conclusions can also be extended to adults' language use of structures in experimental settings (see Roland et al. 2007) for a similar conclusion on adults and their use of structures in corpora).

Frequency of passive and passive RCs: the role of language-internal factors

Passive RCs were already produced by the 3-year-old children and constituted the most frequent structure from age 5 onwards, with no differences regarding its properties across ages. All passive RCs were eventive and, having been lexicalized by a von-PP, were syntactically integrated into the host clause. These long passive variants were produced when required by discourse. While these results are in line with corpus studies reporting passive RCs to be preferred to ORCs, the predominance of passive RCs is still surprising, given that passive is reported to be very rare in adult child-directed speech. Study 2 revealed that passive RCs were almost absent in child-directed speech as well, and that their rate did not increase with the child's age. Moreover, in contrast to the long passives favored by adults and children in Study 1, most passives in child-directed speech were short. Accordingly, neither the high production rate nor the formal properties of the passive RCs elicited in Study 1 can be easily determined by corpus frequencies.

Here, we suggest that participants' choices and the developmental path may be explained by drawing on the notion of syntactic complexity (see de Vincenzi 1991; Friedmann et al. 2009; Contemori and Belletti 2014; a.o.). Informally speaking, whenever there are two (or more) alternative structures, A and B, to express roughly the same meaning, a speaker will prefer the syntactically simpler structure A, requiring fewer ingredients in the syntactic derivation (e.g., Jakubowicz 2011) to B, and children will acquire structure A before structure B. ${ }^{8}$ Crucially, the structures that are, in principle, available in the patientmodifying context are all reported to be infrequent in natural speech data. Accordingly, it is difficult to see how sensitivity to frequency-no matter which flavor-could be of help here in determining language use and acquisition. Focusing on passive RCs and ORCs, we maintain that the former structure is syntactically simpler than the latter and that this leads to the preferred use and early emergence of passive RCs in German. The argument is as follows: whereas in ORCs the patient DP is assumed to cross the agent, resulting in increased difficulty (Friedmann et al. 2009), the patient DP in passive RCs does not cross the agent. Depending on the syntactic analysis, crossing does not occur because of the lack of an agent DP in passives (Baker et al. 1989; Bruening 2013; Alexiadou 2005; Alexiadou and Schäfer 2013, a.o.), or because of smuggling (Collins 2005; Contemori and Belletti 2014). Accordingly, the preference for passive RCs over ORCs may be the reflex of the, possibly universal, principle of relativized minimality according to which ORCs are avoided in favor of SRCs as proposed in Friedmann et al. (2009). We note that the preference for passive RCs may have been promoted by our experimental setting, in which both the agent and the patient were animate. Animate DPs tend to be structurally the subject of a sentence (e.g., Aissen 2003), which may have favored the production of SRCs, which in a patient-modifying context means passive RCs as well as of SEMANTICALLY INAPPROPRIATE RCs. That is, when prompted to modify the patient as in Figure 2 "Which donkey is wearing the hat?", children may tend to treat the modified DP, i.e., the donkey, as the subject of the RC, due to its animacy. This results in the production of a RC with the patient being promoted to the subject of the RC, namely, a passive RC and a semantically inappropriate RC. ${ }^{9}$

We propose that syntactic complexity may also account for the frequency and the acquisition path of SEMANTICALLY INAPPROPRIATE RCS, i.e., SRCs with either the head or

\footnotetext{
8 This is parallel to the rationale for the pronon-noun case mentioned above.

9 Additionally, we cannot exclude that the increase in the use of passive RCs with age is linked to the effect of schooling; a link between schooling and the use of passives has been suggested i.a. by Sánchez Sánchez Walker and Montrul (2021).
} 
the theta role reversed, which were produced by many three- and four-year-olds. SEMANTICALLY INAPPROPRIATE RCS cannot be explained by corpus frequency and, specifically, not by the input children are exposed to. They could serve as a precursor of passive RCs: children who have not yet mastered the relevant ingredients to derive a passive predicate (e.g., see, de Villiers and Villiers 1985; Fritzenschaft 1994; Snyder and Hyams 2015; Contemori and Belletti 2014) may produce SRCs on the patient with active verbal morphology.

In a nutshell, our finding on passive RCs and SEMANTICALLY INAPPROPRIATE RCS attests that there are at least some cases where the most frequent and the less complex grammatical variants do not overlap. The relation between frequency in natural speech and use of a given variant in a specific context is indirect: speakers may opt for the grammatically less complex computation rather than for the most frequent one.

For future research, we may ask whether the principles guiding the adults' choice of a grammatical variant and the principles determining the order of acquisition necessarily have to be the same, as stated by classical frequentist accounts. As a case in point, children's choice of SEMANTICALLY INAPPROPRIATE RCS and pronoun-noun ORCs was not reflected by the adult productions, indicating that adult use and children's acquisition order of structures may be driven by (partially) different principles. This line of research may also have further implications for the long-standing debate between frequentist and generative accounts and more recent accounts integrating both views (e.g., Yang 2015).

\section{Conclusions}

Our elicited production study and the analysis of child-directed speech targeted nominal modification contexts. Both sets of results indicate that the frequency and formal properties of structures that are produced in a specific discourse situation do not always reflect the patterns in natural speech. We argue, first, that for the role of frequency to hold, adults and children would need to consider different domains of its application. These should, apart from the notions of absolute and relative frequency usually discussed in the literature, involve abstract structural parallels and specific structural properties, as well as conversational needs (see also Roland et al. 2007). Second, we propose that, besides frequency, language-internal factors, such as syntactic complexity, are crucial for determining which grammatical variant speakers choose and acquire first. The exact division of labor between frequencies and syntactic complexity in language use and acquisition is still unclear: every domain of human cognition, behavior, and language is undoubtedly affected by frequency effects, but it is not obvious that frequency has any explanatory role in language use and acquisition. It may be that there are several types of frequency (e.g., see, Yang's Tolerance Principle, Yang 2015) or that frequency only comes into play once the language learner has reached the right level of abstraction. After all, the occurrence of critical instances (see Roeper and Villiers 1992) is not equal to the overall frequency of structures.

Author Contributions: Both authors E.S. and P.S. are fully responsible for all parts of the text and the analyses. P.S. conceived and designed the experiment in Study 1. E.S. supervised the transcription and scoring and analyzed the data of both studies. Both authors have read and agreed to the published version of the manuscript.

Funding: The research presented here was conducted in the framework of the project "The Acquisition of (non-)restrictive relative clauses in German" (PI: P. Schulz). The project (SCHU 1983/1-1) was supported by the Deutsche Forschungsgemeinschaft, Forschergruppe 1783 "Relativsätze".

Informed Consent Statement: Informed consent was obtained from all subjects involved in the study.

Acknowledgments: We are grateful to the children who participated in the study, their parents, and their teachers for their support. We would also like to thank Corinna Trabandt, Alexander Thiel, and Barbara Schulz who helped to develop and pilot the experimental task. We are very grateful to Demetrio Rodriguez for his support with the statistical analyses. We thank Ana Perez Leroux 
for helped us to shape our argumentation, and we thank Nadine Beidinger for her help with data management.

Conflicts of Interest: The authors declare no conflict of interest.

\section{Appendix A}

Table A1. Raw scores of PASSIVE RCs produced for contrasting actions and contrasting agent contexts (patient-modifying context only).

\begin{tabular}{ccc}
\hline Groups & Contrasting Actions & Contrasting Agents \\
\hline Age 3 & $13 / 324$ & $12 / 324$ \\
Age 4 & $44 / 372$ & $49 / 372$ \\
Age 5 & $146 / 372$ & $124 / 372$ \\
Age 6 & $148 / 300$ & $125 / 300$ \\
Adults & $207 / 252$ & $223 / 252$ \\
\hline
\end{tabular}

Table A2. Number of passive RCs compared to the total of utterances produced by Leo's mother.

\begin{tabular}{|c|c|c|}
\hline $\begin{array}{l}\text { Child Age } \\
\text { y;m }\end{array}$ & Number of Passive RCs & $\begin{array}{c}\text { Total N of Utterances Leo's } \\
\text { Mother }\end{array}$ \\
\hline $1 ; 11$ & 0 & 2278 \\
\hline 2;00 & 1 & 10,961 \\
\hline $2 ; 1$ & 0 & 6685 \\
\hline $2 ; 2$ & 1 & 7936 \\
\hline $2 ; 3$ & 1 & 7178 \\
\hline $2 ; 4$ & 0 & 10,738 \\
\hline $2 ; 5$ & 3 & 10,021 \\
\hline $2 ; 6$ & 0 & 4689 \\
\hline $2 ; 7$ & 1 & 7801 \\
\hline $2 ; 8$ & 2 & 8446 \\
\hline $2 ; 9$ & 0 & 6438 \\
\hline $2 ; 10$ & 0 & 7461 \\
\hline $2 ; 11$ & 0 & 7962 \\
\hline $3 ; 0$ & 0 & 2473 \\
\hline $3 ; 1$ & 1 & 2258 \\
\hline $3 ; 2$ & 0 & 2004 \\
\hline $3 ; 3$ & 0 & 1513 \\
\hline $3 ; 4$ & 0 & 1978 \\
\hline $3 ; 5$ & 1 & 3930 \\
\hline $3 ; 6$ & 0 & 2376 \\
\hline $3 ; 7$ & 0 & 2918 \\
\hline $3 ; 8$ & 1 & 1883 \\
\hline $3 ; 9$ & 0 & 1553 \\
\hline $3 ; 10$ & 0 & 2385 \\
\hline $3 ; 11$ & 1 & 3007 \\
\hline $4 ; 0$ & 0 & 2875 \\
\hline $4 ; 1$ & 1 & 3279 \\
\hline $4 ; 2$ & 1 & 3236 \\
\hline $4 ; 3$ & 0 & 3119 \\
\hline $4 ; 4$ & 0 & 2756 \\
\hline $4 ; 5$ & 1 & 2582 \\
\hline $4 ; 6$ & 0 & 2627 \\
\hline $4 ; 7$ & 3 & 3025 \\
\hline $4 ; 8$ & 1 & 2794 \\
\hline $4 ; 9$ & 2 & 2492 \\
\hline $4 ; 10$ & 2 & 2032 \\
\hline $4 ; 11$ & 0 & 3099 \\
\hline
\end{tabular}

\section{References}

Abbot-Smith, Kirsten F., and Heike Behrens. 2006. How known constructions influence the acquisition of new constructions: The German periphrastic passive and future constructions. Cognitive Science 30: 995-1026. [CrossRef] 
Adani, Flavia, Heather K. J. van der Lely, Matteo Forgiarini, and Maria Teresa Guasti. 2010. Grammatical feature dissimilarities make relative clauses easier: A comprehension study with Italian children. Lingua 120: 2148-66. [CrossRef] [PubMed]

Adani, Flavia, Marie Sehm, and Andrea Zukowski. 2012. How do German Children and Adults deal with their Relatives. In Advances in Language Acquisition. Edited by Stavroula Stavrakaki, Marina Lalioti and Polyxeni Konstantinopoulou. Cambridge: Cambridge Scholars Publishing, pp. 14-22.

Adani, Flavia, Maja Stegenwallner-Schütz, and Talea Niesel. 2017. The peaceful co-existence of input frequency and structural intervention effects on the comprehension of complex sentences in german-speaking children. Frontiers in Psychology 8: 1590. [CrossRef] [PubMed]

Aissen, Judith. 2003. Differential Object Marking: Iconicity vs. Economy. Natural Language and Linguistic Theory 21: 435-83. [CrossRef]

Alexiadou, Artemis, and Florian Schäfer. 2013. Non-Canonical Passives. Amsterdam: John Benjamins. [CrossRef]

Alexiadou, Artemis. 2005. A Note on Non-Canonical Passives: The Case of the Get-Passive. In Organizing Grammar: Linguistic Studies in Honor of Henk van Riemsdijk. Edited by Hans Broekhuis, Norbert Corver, Riny Huybregts, Ursula Kleinhenz and Jan Koster. Berlin and New York: Mouton de Gruyter, pp. 13-21, ISBN 978-3-11-018850-9.

Ambridge, Ben, Evan Kidd, Caroline F. Rowland, and Anna L. Theakston. 2015. The ubiquity of frequency effects in first language acquisition. Journal of Child Language 42: 239-73. [CrossRef] [PubMed]

Kieburg, Anja, and Petra Schulz. 2010. Input factors in early verb acquisition: Do word order variability and word frequency of verbs matter? In Variation in the input. Studies in Theoretical Psycholinguistics. Edited by Merete Anderssen, Kristine Berentzen and Marit Westergaard. Dordrecht: Springer, vol. 36, pp. 95-127. [CrossRef]

Bader, Markus, and Vasiliki Koukoulioti. 2018. When Object-Subject Order is Preferred to Subject-Object Order: The Case of German Main and Relative Clauses. In Grammar and Corpora 2016. Edited by Eric Fuß, Marek Konopka, Beata Trawinski and Ulrich H. Waßner. Heidelberg: Heidelberg University Publishing, pp. 53-71.

Baker, Mark, Kyle Johnson, and Ian Roberts. 1989. Passive arguments raised. Linguistic Inquiry 20: 219-51. Available online: http:/ / www.jstor.org/stable/4178625 (accessed on 11 June 2020).

Baroni, Marco, Silvia Bernardini, Adriano Ferraresi, and Eros Zanchetta. 2009. The WaCky Wide Web: A collection of very large linguistically processed webcrawled corpora. Language Resources and Evaluation 43: 209-26. [CrossRef]

Bates, Douglas, Martin Maechler, Ben Bolker, and Steve Walker. 2015. Fitting Linear Mixed-Effects Models Using lme4. Journal of Statistical Software 67: 1-48. [CrossRef]

Belletti, Adriana, and Cristiano Chesi. 2014. A syntactic approach toward the interpretation of some distributional frequencies: Comparing relative clauses in Italian corpora and in elicited production. Rivista di Grammatica Generativa 36: 1-28.

Belletti, Adriana, and Joao Costa. 2015. Passive Object Relatives in Italian and Portuguese: Smuggling and intervention. Paper presented at the 12th GALA, Nantes, France, September 10-12.

Belletti, Adriana, Naama Friedmann, Dominique Brunato, and Luigi Rizzi. 2012. Does gender make a difference? Comparing the effect of gender on children's comprehension of relative clauses in Hebrew and Italian. Lingua 122: 1053-69. [CrossRef]

Brandner, Eleonore, and Iris Bräuning. 2013. Relative 'wo' in Alemannic: Only a complementizer? Linguistische Berichte $234:$ 131-69.

Brandt, Silke, Holger Diessel, and Michael Tomasello. 2008. The acquisition of German relative clauses: A case study. Journal of Child Language 35: 325-48. [CrossRef] [PubMed]

Brandt, Silke. 2004. The Acquisition of Relative Clauses in German and English. The Very First Steps. Master's thesis, University of Leipzig, Leipzig, Germany.

Bruening, Benjamin. 2013. By Phrases in Passives and Nominals. Syntax 16: 1-41. [CrossRef]

Bybee, Joan, and Paul Hopper, eds. 2001. Frequency and the Emergence of Linguistic Structure. Amsterdam: John Benjamins. [CrossRef]

Bybee, Joan. 2006. From usage to grammar: The mind's response to repetition. Language 82: 711-33. [CrossRef]

Cinque, Guglielmo. 2017. A note on Romance and Germanic past participle relative clauses. Wellington Working Papers in Linguistics 23: 19-28.

Collins, Chris. 2005. A smuggling approach to the passive in English. Syntax 8: 81-120. [CrossRef]

Contemori, Carla, and Adriana Belletti. 2014. Relatives and Passive Object Relatives in Italian speaking children and adults: Intervention in production and comprehension. Applied Psycholinguistics 35: 1021-53. [CrossRef]

de Villiers, Jill G., and Peter A. de Villiers. 1985. The acquisition of English. In The Crosslinguistic Study of Language Acquisition, Volume 1: The Data. Edited by Dan I. Slobin. Hillsdale: Lawrence Erlbaum Associates, pp. 27-141, ISBN 9780898593679.

de Vincenzi, Marica. 1991. Syntactic Parsing Strategies in Italian. Studies in Theoretical Psycholinguistics 12. Dordrecht: Springer. [CrossRef]

Diessel, Holger, and Michael Tomasello. 2005. A new look at the acquisition of relative clauses. Language 81: 1-25. [CrossRef]

Diessel, Holger. 2009. On the role of frequency and similarity in the acquisition of subject and non-subject relative clauses. In Syntactic Complexity: Diachrony, Acquisition, Neurocognition, Evolution. Edited by Talmy Givón and Masayoshi Shibatani. Amsterdam: John Benjamins, pp. 251-76. [CrossRef]

Diessel, Holger. 2019. The Grammar Network. How Linguistic Structure Is Shaped by Language Use. Cambridge: Cambridge University Press, ISBN 9781108498814.

Doherty, Monika. 2006. Structural Propensities. Translating Nominal Word Groups from English into German. Amsterdam: John Benjamins. [CrossRef] 
Fabricius-Hansen, Cathrine. 2010. Adjektiv-/Partizipialattribute im diskursbezogenen Vergleich. Deutsche Sprache 38: 175-92. [CrossRef]

Fleischer, Jürg. 2004. A typology of relative clauses in German dialects. In Dialectology Meets Typology: Dialect Grammar from a Cross-Linguistic Perspective. Edited by Bernd Kortmann. Berlin and New York: Mouton de Gruyter, pp. 211-43. [CrossRef]

Fox, Annette V. 2006. TROG-D. In Test zur Überprüfung des Grammatikverständnisses. Idstein: Schulz-Kircher Verlag, ISBN 978-3-82480355-2.

Friedmann, Naama, Adriana Belletti, and Luigi Rizzi. 2009. Relativized relatives: Types of intervention in the acquisition of A-bar dependencies. Lingua 119: 67-88. [CrossRef]

Fritzenschaft, Agnes. 1994. Activating Passives in Child Grammar. In How Tolerant is Universal Grammar. Edited by Rosemarie Tracy and Elsa Lattey. Tübingen: Niemeyer, pp. 155-84. [CrossRef]

Fritzenschaft, Agnes, Ira Gawlitzek-Maiwald, Rosemarie Tracy, and Susanne Winkler. 1990. Wege zur komplexen Syntax. Zeitschrift für Sprachwissenschaft 9: 52-134. [CrossRef]

Gärtner, Hans-Martin. 2001. Are there V2 relative clauses in German? Journal of Comparative Germanic Linguistics 3: 97-141. [CrossRef]

Gavarrò, Anna, Arnau Cunill, Míriam Muntané, and Marc Reguant. 2012. The acquisition of Catalan relatives: Structure and processing. Revue Roumaine de Linguistique 57: 183-201.

Gordon, Peter C., Randall Hendrick, and William H. Levine. 2002. Memory-load interference in syntactic processing. Psychological Science 13: 425-30. [CrossRef]

Grimm, Hannelore. 2001. Sprachentwicklungstest für Drei- bis Fünfjährige Kinder-SETK 3-5. Göttingen: Hogrefe.

Guasti, Maria Teresa, and Anna Cardinaletti. 2003. Relative clause formation in Romance child production. Probus 15: 47-89. [CrossRef]

Håkansson, Gisela, and Kristina Hansson. 2000. Comprehension and production of relative clauses: A comparison between Swedish impaired and unimpaired children. Journal of Child Language 27: 313-33. [CrossRef]

Hansen, Sandra, and Silvia Hansen-Schirra. 2012. Grammatical shifts in English-German noun phrases. In Cross-Linguistic Corpora for the Study of Translations_-Insights from the Language Pair English-German. Edited by Silvia Hansen-Schirra, Stella Neumann and Erich Steiner. Berlin and Boston: De Gruyter, pp. 133-46. [CrossRef]

Hansen-Schirra, Silvia, Stella Neumann, and Erich Steiner. 2007. Cohesive explicitness and explicitation in an English-German translation corpus. Language in Contrast 7: 241-66. [CrossRef]

Hirschberg, Tim, Carolin Reinhert, Anna Roth, and Caroline Féry. 2014. Relative clauses in colloquial and literary German: A contrastive corpus-based study. Linguistische Berichte 240: 405-45.

Jakubowicz, Celia. 2011. Measuring derivational complexity: New evidence from typically developing and SLI learners of L1 French. Lingua 121: 339-51. [CrossRef]

Jensen de Lopez, Kristine, Lone Sundahl Olsen, and Vasiliki Chondrogianni. 2014. Annoying Danish relatives: Comprehension and production of relative clauses in Danish typically developing children and children with SLI. Journal of Child Language 41: 51-83. [CrossRef] [PubMed]

Kidd, Evan, Silke Brandt, Elena Lieven, and Michael Tomasello. 2007. Object relatives made easy: A crosslinguistics comparison of the constraints influencing young children's processing of relative clauses. Language and Cognitive Processes 22: 860-97. [CrossRef]

Kim, Chae Eun, and William OGrady'. 2016. Asymmetries in children's production of relative clauses: Data from English and Korean. Journal of Child Language 43: 1038-71. [CrossRef]

Lenth Russell, V. 2016. Least-Squares Means: The R Package lsmean. Journal of Statistical Software 69: 1-33. [CrossRef]

Lübbe, Anja, and und Irene Rapp. 2011. Aspekt, Temporalität und Argumentstruktur bei attributiven Partizipien des Deutschen. Zeitschrift für Sprachwissenschaft 30: 259-99. [CrossRef]

MacWhinney, Brian. 2000. The CHILDES Project: Tools for Analyzing Talk, 3rd ed. Mahwah: Lawrence Erlbaum Associates, ISBN 0-8058-2995-4.

Mak, Willem M., Wietske Vonk, and Herbert Schriefers. 2002. The influence of animacy on relative clause processing. Journal of Memory and Language 47: 50-68. [CrossRef]

Mak, Willem M., Wietske Vonk, and Herbert Schriefers. 2006. Animacy in processing relative clauses: The hikers that rocks crush. Journal of Memory and Language 54: 466-90. [CrossRef]

Mills, Anne. E. 1985. The acquisition of German. In The Crosslinguistic Study of Language Acquisition vol. 1. Edited by Dan I. Slobin. Hillsdale: Lawrence Erlbaum, pp. 141-254, ISBN 9780898593679.

Novogrodsky, Rama, and Naama Friedmann. 2006. The production of relative clauses in SLI: A window to the nature of the impairment. Advances in Speech-Language Pathology 8: 364-75. [CrossRef]

Pakkanen-Kilpiä, Kirsi. 2004. Zur Verwendbarkeit des Partizips II als Attribut. Frankfurt am Main: Peter Lang, Finnische Beiträge zur Germanistik, p. 11, ISBN 978-3-631-2158-8.

R Core Team. 2016. R: A Language and Environment for Statistical Computing; Vienna: R Foundation for Statistical Computing. Available online: https:/ / www.R-project.org/ (accessed on 19 February 2021).

Roeper, Tom, and Jill de Villiers. 1992. The One Feature Hypothesis for Acquisition. Manuscript. Amherst, MA, USA: University of Massachusetts.

Roland, Douglas, Frederic Dick, and Jeffrey L. Elman. 2007. Frequency of basic English grammatical structures: A corpus analysis. Journal of Memory and Language 57: 348-79. [CrossRef] 
Rothweiler, Monika. 1993. Der Erwerb von Nebensätzen im Deutschen: Eine Pilotstudie. Tübingen: Niemeyer, Linguistische Arbeiten, p. 302, ISBN 3484303026.

Sánchez Walker, Noelia, and Silvina Montrul. 2021. Language Experience Affects Comprehension of Spanish Passive Clauses: A Study of Heritage Speakers and Second Language Learners. Languages 6: 2. [CrossRef]

Sanfelici, Emanuela, Petra Schulz, and Corinna Trabandt. 2017. On German V2 "relative clauses": Linguistic theory meets acquisition. In Syntactic Complexity from a Language Acquisition Perspective. Edited by Elisa di Domenico. Cambridge: Cambridge Scholars Press, pp. 63-104.

Schulz, Petra, and Rosemarie Tracy. 2018. Revisiting the tolerance of Universal Grammar. In T.O.M. and Grammar. Thoughts on Mind and Grammar: A Festschrift in honor of Tom Roeper. University of Massachusetts Occasional Papers in Linguistics (UMOP). Edited by Bart Hollebrandse, Jaieun Kim, Ana T. Pérez-Leroux and Petra Schulz. Amherst: University of Massachusetts, Graduate Linguistics Student Association, vol. 41, pp. 129-45, ISBN 1729520650.

Snyder, William, and Nina Hyams. 2015. Minimality effects in children's passives. In Structures, Strategies and Beyond: Studies in Honour of Adriana Belletti. Edited by Elisa Di Domenico, Cornelia Hamann and Simona Matteini. Amsterdam: John Benjamins, pp. 343-68. [CrossRef]

Struckmeier, Volker. 2007. Attribute im Deutschen. Zu ihren Eigenschaften und ihrer Position im grammatischen System. Berlin and Boston: De Gruyter. [CrossRef]

Thornton, Rosalind J. 1990. Adventures in Long-Distance Moving: The Acquisition of Complex Wh-Questions. Doctoral dissertation, University of Connecticut, Storrs, CT, USA.

Tjung, Yassir. 2006. The formation of relative clauses in Jakarta Indonesian: A subject-object asymmetry. Ph.D. dissertation, University of Delaware, Newark, DE, USA.

Weber, Heinrich. 1971. Das Erweiterte Adjektiv- und Partizipialattribut im Deutschen. München: Hueber, Linguistische Reihe, p. 4.

Yang, Charles. 2015. For and against frequencies. Journal of Child Language 42: 287-193. [CrossRef] [PubMed]

Yatsushiro, Kazuko, and Ulli Sauerland. 2019. How to be Brief: Children's and Adults' Application of Grice's Brevity Maxim in Production. Languages 4: 18. [CrossRef]

Zifonun, Gisela, Ludger Hoffmann, and Bruno Strecker. 1997. Grammatik der deutschen Sprache. Berlin: De Gruyter. [CrossRef]

Zombolou, Katerina, and Artemis Alexiadou. 2015. The emergence of passives in early L1 German. Paper presented at SLE Conference, Societas Linguistica Europea-University of, Leiden, Leiden, NL, USA, September 2-5. 